\title{
Polymer-assisted in-situ thermal reduction of silver precursors: a solventless route for silver nanoparticles-polymer composites
}

Dambarudhar Parida, ${ }^{a}$ Pietro Simonetti, ${ }^{a}$ Ruggero Frison, ${ }^{b}$ Ezgi Bülbül, ${ }^{a}$ Stefanie Altenried, ${ }^{\mathrm{c}}$ Yadira Arroyo, ${ }^{\mathrm{d}}$ Zoltán Balogh-Michels, ${ }^{\mathrm{b}}$ Walter Caseri, ${ }^{\mathrm{e}}$ Qun Ren, ${ }^{\mathrm{c}}$ Rudolf Hufenus, ${ }^{\text {a* }}$ Sabyasachi Gaan ${ }^{\text {a* }}$

${ }^{a}$ Advanced Fibers, Empa Swiss Federal Laboratories for Materials Science and Technology, St Gallen, CH9014, Switzerland.

${ }^{\mathrm{b} C e n t e r}$ for X-Ray Analytics, Empa, Swiss Federal Laboratories for Materials Science and Technology, Dubendorf, CH-8600, Switzerland.

'Biointerfaces, Empa Swiss Federal Laboratories for Materials Science and Technology, St Gallen, CH9014, Switzerland.

${ }^{\mathrm{d} A d v a n c e d ~ M a t e r i a l s ~ a n d ~ S u r f a c e s, ~ E m p a, ~ S w i s s ~ F e d e r a l ~ L a b o r a t o r i e s ~ f o r ~ M a t e r i a l s ~ S c i e n c e ~ a n d ~}$ Technology, Dubendorf, CH-8600, Switzerland.

eDepartment of Materials, ETH Zürich, Zürich, CH-8093, Switzerland.

*Corresponding authors.

sabyasachi.gaan@empa.ch

rudolf.hufenus@empa.ch

This document is the accepted manuscript version of the following article:

Parida, D., Simonetti, P., Frison, R., Bü7bü1, E., Altenried, S., Arroyo, Y., ... Gaan, S. (2019). Polymer-assisted in-situ thermal reduction of silver precursors: a solventless route for silver nanoparticles-polymer composites. Chemical Engineering Journa1, 123983. https://doi.org/10.1016/j.cej.2019.123983

This manuscript version is made available under the CC-BY-NC-ND 4.0

1icense http://creativecommons.org/1icenses/by-nc-nd/4.0/ 


\section{Abstract}

A simple one-step solventless in-situ reduction method was developed to prepare silver nanoparticle (AgNP) based polymer composites using different silver precursors and thermoplastic polymers. This method utilizes the mild reducing environment of thermoplastic polymer melts to convert silver precursors to AgNPs during the extrusion process. Complete reduction of $\mathrm{Ag}_{2} \mathrm{O}$ with broad $\mathrm{AgNP}$ size distribution $(20 \pm 18 \mathrm{~nm}$ ) in polyamide 6 (PA6) was obtained after 5 min processing. For same matrix, the uniformity of AgNPs improved significantly after 10 min processing time, associated with a slight increase in the particle diameter $(26 \pm 9 \mathrm{~nm})$. No significant impact of in-situ AgNP synthesis method on chemical and macromolecular characteristics of polyamide 6 was detected. When this method was used to synthesize AgNPs in polylactic acid and polypropylene, the influence of surface energy of polymer melt was evident. Reduction of $\mathrm{Ag}_{2} \mathrm{O}$ in polylactic acid (at $165^{\circ} \mathrm{C}$ ) was slower compared to PA6 and $95 \pm 3 \% \mathrm{Ag}_{2} \mathrm{O}$ reduction was achieved after 10 min of processing. When polypropylene was used as the matrix, only $60 \%$ reduction of $\mathrm{Ag}_{2} \mathrm{O}$ was achieved, possibly due to poor wetting of the silver precursor, owing to the low surface energy of polypropylene. AgNP-PA6 composites were also successfully prepared using $\mathrm{Ag}_{2} \mathrm{CO}_{3}$ and $\mathrm{Ag}$-palmitate as precursors. To demonstrate the potential application of such composites in food packaging, the silver release and antibacterial activity of AgNP-PA 6 composite were also studied. Though the composites released 500 times less silver compared to the permitted limits of different safety standards, they exhibited an excellent antibacterial activity against a typical food pathogen (Listeria monocytogenes) already at a low level of AgNP loading i.e. 0.5 wt.\%.

Keywords: Silver nanoparticles, nanocomposites, solventless process, in-situ reduction, thermal reduction, antimicrobial 


\section{Introduction}

Silver nanoparticles (AgNPs) based polymer composites have received unprecedented attention, because of their unmatched physicochemical and biological properties [1-5] and these composites are commercially exploited in the consumer industry.[4, 6-8] In the wake of food preservation and health safety, AgNPs have found wide acceptability in protective polymer composite based packaging for food[9] and medical devices.[10] AgNPs used in these composites are prepared by chemical or biological routes in the presence of stabilizers and large quantities of solvents to prevent aggregation.[11-16] Solvent casting or melt blending of thermoplastic polymers with AgNPs remains dominant techniques to prepare these composites.[17-21] Presence of residual reducing agents, solvents and stabilizers in the composite increases the risk of contaminant migration to food well beyond the permitted limit of $10 \mathrm{mg} / \mathrm{dm}^{2}$ as per European regulation for plastic packaging (EU No. 10/2011). Moreover, tendency of unstabilized AgNPs to aggregate during melt mixing results in decrease in their efficacy.[22, 23] Both in solvent casting and melt mixing process, nanocomposites are prepared in multiple solvents and via energy consuming steps. At the time when manufacturing processes are scrutinized under the benchmark of environmental impact, such techniques of composite preparation are not considered sustainable. To meet requirements of sustainable processes and health safety standards, several in-situ AgNP synthesis methods are reported to eliminate the use of reducing agents and stabilizers.[24-33]

Due to their auto-oxidative ability polymers such as polyvinyl alcohol and poly(cardanyl acrylate) were used as matrix as well as reducing agent for in-situ preparation of AgNP composites.[26, 27, 34] Natural polymer such as modified chitosan has also been used as a matrix for in-situ reduction of silver precursors without reducing agents.[31-33] Despite their simplistic approach, these methods are known for their long processing time and very low silver content in the composite. The release of $\mathrm{H}_{2}$ during processing (imidization) of polyimides offers an alternative route for preparation of nanocomposites with higher silver loading in a relatively short processing time.[29, 
35-37] In order to decrease the processing time further and increase the silver loading, photochemical reduction methods have also been explored and AgNP-polymer composites were prepared successfully within few minutes.[38-40] Despite such advantages, photochemical methods are only suitable for preparation of thin AgNP-polymer composites (few microns). Although all these in-situ techniques avoid several intermediate steps and achieve uniform distribution of AgNPs, complete elimination of solvent during in-situ AgNP-composite preparation is still a challenge and suffers from high energy consumption.

In this context, in-situ synthesis of silver nanoparticles during melt processing of thermoplastics seems to be a viable solvent free alternative. AgNP-polymer composites via melt processing using silver precursors like silver acetate having lower decomposition temperature $\left(\sim 200{ }^{\circ} \mathrm{C}\right)[41]$ than melting point of polymers has been demonstrated.[23, 42, 43] It is worth mentioning here that, acidic products released during decomposition of silver acetate not only pose a serious health risk but also can change the polymer melt characteristics, accelerate its decomposition and corrosion of processing machinery can't be avoided. Moreover, risk of accumulating decomposition by-products in the composites increases with the increased silver precursor loading. These factors limit the concentration of silver acetate loading $(\sim 2 \%)$ during the melt processing with the polymer. On the other hand, precursors like $\mathrm{Ag}_{2} \mathrm{O}$ release only $\mathrm{O}_{2}$ during decomposition and have a higher active silver content ( $94 \%)$ compared to other inorganic silver compounds. However, thermal decomposition temperature of $\mathrm{Ag}_{2} \mathrm{O}$ is similar to or higher than decomposition temperature of many thermoplastic polymers. Understanding the thermal reduction mechanism of $\operatorname{Ag}_{2} \mathrm{O}$ is the key to design of industrially relevant novel manufacturing routes for clean AgNP-polymer composite production.

It is well established that, thermal reduction of silver precursor like $\mathrm{Ag}_{2} \mathrm{O}\left(300-400{ }^{\circ} \mathrm{C}\right)$ takes place in two distinct steps of induction and autocatalytic reduction also known as the acceleratory period.[44-46] Plausible explanation of induction period is the formation of volatiles $\left(\mathrm{O}_{2}\right)$ and low volatiles (silver vapor) followed by the condensation of silver vapor $\left(\mathrm{Ag}^{0}\right)$ to form two-dimensional 
interface. $[45,46]$ The acceleratory period is the result of partial transfer of energy released at the interface during the induction phase to silver precursors. The measured activation energy $\left(E_{a}\right)$ for such thermal reduction is $\sim 120 \mathrm{~kJ} \mathrm{~mol}^{-1}$. Interestingly, when $\mathrm{H}_{2}$ was used during the thermal reduction of $\mathrm{Ag}_{2} \mathrm{O}$, a significant decrease in the $E_{a}\left(\sim 60 \mathrm{~kJ} \mathrm{~mol}^{-1}\right)$ was achieved which also decreased the reduction temperature to $140-150{ }^{\circ} \mathrm{C} .[47,48]$ Similar decrease in $E_{a}$ and decomposition temperature was also observed during the reduction of silver acetate.[41]

Herein, a single-step solvent-less process for AgNP-polymer composite preparation is reported which combines the basic understanding of the thermal reduction mechanism of Ag precursors with the mild reducing environment of molten polymers.[49-52] This concept was proven for the combination of various thermoplastic matrices such as polyamide-6 (PA6), polypropylene (PP) and polylactic acid (PLA) with silver precursors like $\mathrm{Ag}_{2} \mathrm{O}, \mathrm{Ag}_{2} \mathrm{CO}_{3}\left(\mathrm{Ag}_{\mathrm{CAR}}\right)$ and silver palmitate $\left(\mathrm{Ag}_{\mathrm{PAL}}\right)$. These polymers were selected based on their surface free energy at the melting point, which influences the silver precursor-polymer compatibility and eventually the nanoparticle formation. Apart from being an environmental friendly process, this method enables clean work environment, safe handling and prevents unnecessary exposure to nanoscale Ag. Furthermore, the silver release behavior of the prepared nanocomposites was also studied and the prepared nanocomposites possess desired antibacterial property against food pathogens such as Listeria monocytogenes even at a very low silver content (0.5 wt.\%).

\section{Experimental}

\subsection{Materials}

Polyamide-6 (PA6, Grilon A26® by Ems-Chemie); polypropylene (PP, PPH 10099®, Total Petrochemicals) and polylactic acid (PLA, Innofil3D PLA ${ }^{\circledR}$, Innofil3D) were used after overnight vacuum drying at $100{ }^{\circ} \mathrm{C}$. Silver (I) oxide $\left(\mathrm{Ag}_{2} \mathrm{O}, 99.0 \%\right)$ and Silver carbonate $\left(\mathrm{Ag}_{2} \mathrm{CO}_{3}, 99.0 \%\right)$ were purchased from ABCR $\mathrm{GmbH}$ and Sigma-Aldrich respectively. Silver palmitate 
$\left(\mathrm{C}_{16} \mathrm{H}_{31} \mathrm{O}_{2} \mathrm{Ag}\right)$ was synthesized from $\mathrm{Ag}_{2} \mathrm{O}$ and palmitic acid in toluene. Detailed synthesis and characterization of silver palmitate $\left(\mathrm{Ag}_{\mathrm{PAL}}\right)$ are described in Sec. S1 of the supplementary information (SI). All Silver precursors were dried overnight under vacuum at $100{ }^{\circ} \mathrm{C}$.

Table 1. Processing conditions and silver precursors used for preparation of AgNP-polymer composites.

\begin{tabular}{|c|c|c|c|c|c|}
\hline \multirow{2}{*}{ Entries } & \multirow{2}{*}{ Polymer } & \multirow{2}{*}{$\begin{array}{c}\text { Precursor } \\
\text { [wt.\%] }\end{array}$} & \multicolumn{2}{|c|}{ Processing } & \multirow{2}{*}{$\begin{array}{c}\text { Sample } \\
\text { name }\end{array}$} \\
\hline & & & Temp. $\left({ }^{\circ} \mathrm{C}\right)$ & Time (min.) & \\
\hline 1 & PA6 & $\mathrm{Ag}_{2} \mathrm{O}[\mathbf{2 0}]$ & 240 & 5 & 5PA $\mathbf{A}_{200 x}$ \\
\hline 2 & PA6 & $\mathrm{Ag}_{2} \mathrm{O}[20]$ & 240 & 10 & $10 P A_{200 x}$ \\
\hline 3 & PA6 & $\mathrm{Ag}_{2} \mathrm{O}[\mathbf{2 0}]$ & 240 & 30 & 30PA $\mathbf{A}_{200 x}$ \\
\hline 4 & PA6 & - & 240 & 10 & 10PA \\
\hline 5 & PA6 & - & 240 & 30 & 30PA \\
\hline \multicolumn{6}{|c|}{ Other polymers } \\
\hline 6 & PP & - & 200 & 10 & $10 \mathrm{PP}$ \\
\hline 7 & PP & $\mathrm{Ag}_{2} \mathrm{O}[\mathbf{2 0}]$ & 200 & 10 & $10 P_{200 x}$ \\
\hline 8 & PLA & - & 165 & 10 & 10PLA \\
\hline 9 & PLA & $\mathrm{Ag}_{2} \mathrm{O}[\mathbf{2 0}]$ & 165 & 10 & 10PLA $A_{200 x}$ \\
\hline \multicolumn{6}{|c|}{ Other Ag precursors } \\
\hline 10 & PA6 & $\mathrm{Ag}_{2} \mathrm{O}[\mathbf{1 0}]$ & 240 & 10 & $10 P A_{100 x}$ \\
\hline 11 & PA6 & $\mathrm{Ag}_{2} \mathrm{CO}_{3}[\mathbf{1 0}]$ & 240 & 10 & $10 P A_{C A R}$ \\
\hline 12 & PA6 & $\mathrm{C}_{16} \mathrm{H}_{31} \mathrm{O}_{2} \mathrm{Ag}[\mathbf{1 0}]$ & 240 & 10 & $10 P A_{P A L}$ \\
\hline
\end{tabular}

\subsection{Methods}

AgNP-polymer composites were prepared by melt-kneading of polymers and silver precursors in a laboratory internal mixer (Haake Rheomix 600 OS) equipped with a twin Banbury type rotors. Compounding temperature was kept slightly higher than the melting temperature of the polymer to achieve proper mixing without compromising the polymer quality. Initially, the polymer was introduced into the mixing chamber (volume $69 \mathrm{~cm}^{3}$ ) through a top-mounted hopper and processed with a speed of $30 \mathrm{rpm}$ for 2 minutes prior to addition of silver precursor. After addition of the silver precursor, the mixture was melt-kneaded for a specified duration. Then, the molten AgNPPolymer composite was removed from the Rheomixer and kept at room temperature for $4-5 \mathrm{~h}$. A portion of AgNP-polymer composite was converted to powder by cryo-milling for different 
characterization. Processing conditions and nomenclature of AgNP-polymer composite samples prepared in this work are summarized in Table 2.

\subsection{Characterizations}

Thermogravimetric analysis (TGA) was performed with a TGA 209 F1 Iris (Netzsch) instrument under $\mathrm{N}_{2}$ atmosphere and air (unless mentioned) with a heating rate of $10{ }^{\circ} \mathrm{C} \mathrm{min}-1$. Temperature range of $25{ }^{\circ} \mathrm{C}$ to $800{ }^{\circ} \mathrm{C}$ was used for TGA analysis. To study the thermal reduction of $\mathrm{Ag}_{2} \mathrm{O}$ in the presence of polymers, the required quantity of $\mathrm{Ag}_{2} \mathrm{O}$ and polymer powder was mixed prior to the thermogravimetric analysis.

UV-visible spectra of AgNP-polymer composite solution in hexafluoro-2-propanol (1 mg/ml) was recorded in a Cary $50 \mathrm{BIO}$ UV-vis Spectrophotometer using quartz cuvette $(1 \mathrm{~cm})$. UV-vis spectra of respective polymer solutions and $\mathrm{Ag}_{2} \mathrm{O}$ powder were also recorded in hexafluoro-2-propanol. X-ray diffraction (XRD) patterns were recorded with a Panalytical XPert ${ }^{3}$ Powder instrument, operating at a voltage of $40 \mathrm{kV}$ and a current of $40 \mathrm{~mA}$ with $\mathrm{Cu} / \mathrm{K}_{\mathrm{a}}$ radiation having a wavelength of $1.5406 \AA$. XRD patterns were recorded over an angular range $(2 \theta)$ of $5^{\circ}$ to $80^{\circ}$. The sample coherent domain size was estimated using the Scherrer equation.[53] The instrumental contribution was estimated measuring the diffraction pattern of $\mathrm{LaB}_{6}$ reference material and taken into account within Topas software.[54]

Transmission electron microscopic (TEM) images were recorded in a TEM/STEM JEOL JEM $2200 \mathrm{fs}$ microscope operating at $200 \mathrm{kV}$ equipped with an energy-dispersive $\mathrm{X}$-ray spectrometer. Samples were prepared by putting a drop of composite dispersion in ethanol $(0.5 \mathrm{mg} / \mathrm{ml})$ on a Lacey Carbon film copper TEM grids. Prior to preparation of composite dispersion, the composites were cryo-milled to get a fine powder. 200 particles at random location were analyzed by Image $\mathrm{J}$ to determine the particle size and distribution. 
Particle size of silver nano particles in AgNP-polymer composites was analyzed by dynamic light scattering (DLS) at $25^{\circ} \mathrm{C}$ using Malvern Zetasizer ZS90 equipment. Composites were dissolved in hexafluoro-2-propanol by stirring for 4 hours at a concentration of $1.0 \mathrm{mg} / \mathrm{ml}$ and quartz cuvette was used for DLS measurements.

Energy dispersive X-Ray spectroscopy (EDX) mapping experiments were conducted on a Hitachi S-4800 Scanning Electron Microscope (SEM) operating at accelerating voltages of $20 \mathrm{kV}$. As prepared composite samples were coated with $\mathrm{Au} / \mathrm{Pd}(5 \mathrm{~nm})$ prior to analysis.

FTIR spectra were recorded on a Bruker FT-IR in transmission mode using films of nanocomposites prepared by solution casting and vacuum drying at $50{ }^{\circ} \mathrm{C}$ for 48 hours prior to analysis.

Molecular weight and molecular weight distribution (PDI) of PA6 samples were determined by gel permeation chromatography (GPC), using THF as the mobile phase $\left(1 \mathrm{ml} / \mathrm{min}\right.$.) at $30^{\circ} \mathrm{C}$. The GPC column was calibrated with Broad-Standard-Calibration-Method using polyamide standards. To make PA6 soluble in THF, trifluoroacetylation of PA6 (100 mg) was carried out with trifluoroacetic acid anhydride (TFAA, $0.8 \mathrm{ml})$ in dichloromethane $(3 \mathrm{ml})$ at room temperature for 16 hours. Modified PA6 was recovered after evaporating the solvent in rotary evaporator $\left(40{ }^{\circ} \mathrm{C}\right)$ and 0.5 wt.\% of modified PA6 in THF was used for GPC analysis.

Silver release behavior of AgNP-polymer composites was determined using PA6 based composites films having different silver content $(0.05,0.1$ and $0.5 \%)$. These films were prepared by spin coating on a circular glass slide $(\varnothing=2.5 \mathrm{~cm})$ to support the film. Prior to spin coating, required quantity of AgNP-PA6 composite and virgin PA6 were dissolved in hexafluoro-2-propanol by stirring overnight at room temperature to achieve $10 \mathrm{wt} \%$ of solid content and targeted silver content. Then, $0.5 \mathrm{ml}$ of this solution was deposited on the slide and was rotated for $60 \mathrm{~s}$ at $1000 \mathrm{rpm}$ to get a film. Hexafluoro-2-propanol was removed by keeping the film at room temperature for 4 hours followed by overnight vacuum drying at $80^{\circ} \mathrm{C}$. Composite film thickness was determined by SEM analysis (see Sec. S7) and actual silver content of spin coated films was determined by inductively coupled 
plasma optical emission spectroscopy (ICP-OES) as summarized in table S3. For silver release study, a media was prepared by mixing $50 \mathrm{ml}$ of Fetal bovine serum (FBS, Sigma-Aldrich) in 500 $\mathrm{ml}$ of Dulbecco's modified Eagle's medium (DMEM, Sigma-Aldrich). Then, composite films of 2.5 $\mathrm{cm}$ diameter were dipped in $4 \mathrm{ml}$ of the prepared medium in a PP lidded tubes maintained at $37^{\circ} \mathrm{C}$. After the set time, the medium was collected and diluted with required quantity of $\mathrm{HNO}_{3}(2 \%)$ prior to determination of Ag release by ICP-OES. 4 set of samples were prepared for each test duration. Antibacterial assays. The typical food pathogen Listeria monocytogenes DSM 15675 was used for the antibacterial activity studies. The polymer films prepared in this work were punched to a size of $6 \mathrm{~mm}$ diameter and sterilized for $20 \mathrm{~min}$ under UV $\left(254 \mathrm{~nm}, 100 \mu \mathrm{W} / \mathrm{cm}^{2}\right.$, Kojair Tech Oy, $18541 \mathrm{UV}-$ Valo, Finland). For agar diffusion test, the exponential growing $L$. monocytogenes of about $10^{7}$ colony forming units $(\mathrm{CFU} / \mathrm{ml})$ were spread over Brain Hear Infusion (BHI, Sigma-Aldrich) plate to create a bacterial lawn. The polymer samples were put on top of the agar plates, which were then incubated at $37^{\circ} \mathrm{C}$ for 24 $\mathrm{h}$ for observation of inhibition zones around the samples.

For contact killing test the following method was used. Briefly, an exponential growing bacterial culture was prepared in BHI at $37{ }^{\circ} \mathrm{C}$ and $160 \mathrm{rpm}$. The culture was then diluted with sterile phosphate-buffered saline (PBS, Sigma-Aldrich) to $\mathrm{OD}_{600 \mathrm{~nm}}$ of 0.01 (corresponding to $10^{6} \mathrm{CFU} / \mathrm{mL}$ ). $50 \mu$ of bacterial suspension was loaded onto the samples with a diameter of $6 \mathrm{~mm}$, incubated at $37^{\circ} \mathrm{C}$ for $2 \mathrm{~h}$. The suspension was removed and the samples were washed twice with $225 \mu 1$ PBS to remove the non-adhered bacteria. To determine the adherent viable cells on the sample surfaces, $100 \mu 1$ PBS was added to the washed samples, followed by sonication for $5 \mathrm{~min}$ in an ice/water bath (Bransonic 52, Branson Ultrasonics SA, Carouge, Switzerland) at a frequency of $40 \mathrm{kHz}$. Serial dilutions were plated on BHI agar plates. All plates were incubated at $37{ }^{\circ} \mathrm{C}$ overnight to give an estimate of viable cell count as CFU/mL. Statistical analyses were performed by utilizing unpaired and two-tailed Student's t-test for comparison between two groups. 


\section{Results and discussion}

Silver precursors such as $\mathrm{Ag}_{2} \mathrm{O}, \mathrm{Ag}_{2} \mathrm{CO}_{3}$ and $\mathrm{Ag}_{\mathrm{PAL}}$ were chosen as precursors to avoid the release of any potentially toxic fumes during the reduction process. These selected precursors can only release $\mathrm{O}_{2}, \mathrm{CO}$ or $\mathrm{CO}_{2},[55]$ which are much safer by-products than acids, $[56,57]$ formaldehyde and $\mathrm{NO}_{2}[58]$ released during thermal decomposition of other silver precursors. Widely used thermoplastics such as PA6, PP and biodegradable polyester like PLA were selected as polymer matrices. Initially, the thermal reduction of $\mathrm{Ag}_{2} \mathrm{O}$ was studied by thermogravimetric analysis (TGA) in the presence and absence of polymers (Fig. 1 and S2). In the absence of polymer, $\operatorname{Ag}_{2} \mathrm{O}$ decomposed to metallic silver $\left(\mathrm{Ag}^{0}\right)$ at around $380{ }^{\circ} \mathrm{C}$, observed as a sharp mass loss during thermogravimetric analysis (Fig. S2).[46, 48] Interestingly, when $\mathrm{Ag}_{2} \mathrm{O}$ (10 wt.\%) was heated in presence of polymers, a sharp mass loss of about $1-2 \%$ was observed at a much lower temperature (Fig. 1) compared to the decomposition temperature of $\mathrm{Ag}_{2} \mathrm{O}$ alone. Based on the theoretical silver content in $\mathrm{Ag}_{2} \mathrm{O}$ (Fig. S2), $0.6 \%$ mass loss is expected at $10 \% \mathrm{Ag}_{2} \mathrm{O}$ loading in a polymer to achieve complete reduction. In the case of $\mathrm{Ag}_{2} \mathrm{O}-\mathrm{PA} 6$ mixture, the onset of mass loss was observed after $170{ }^{\circ} \mathrm{C}$ and took nearly 7 minutes to reach a stable mass prior to degradation. As observed in the TGA, a mass loss of $2 \%$ in $\mathrm{Ag}_{2} \mathrm{O}-\mathrm{PA} 6$ mixture instead of $0.7 \%$ can be attributed to combined release of $\mathrm{O}_{2}$ during the reduction of $\mathrm{Ag}_{2} \mathrm{O}$ and the moisture absorbed by PA6. 

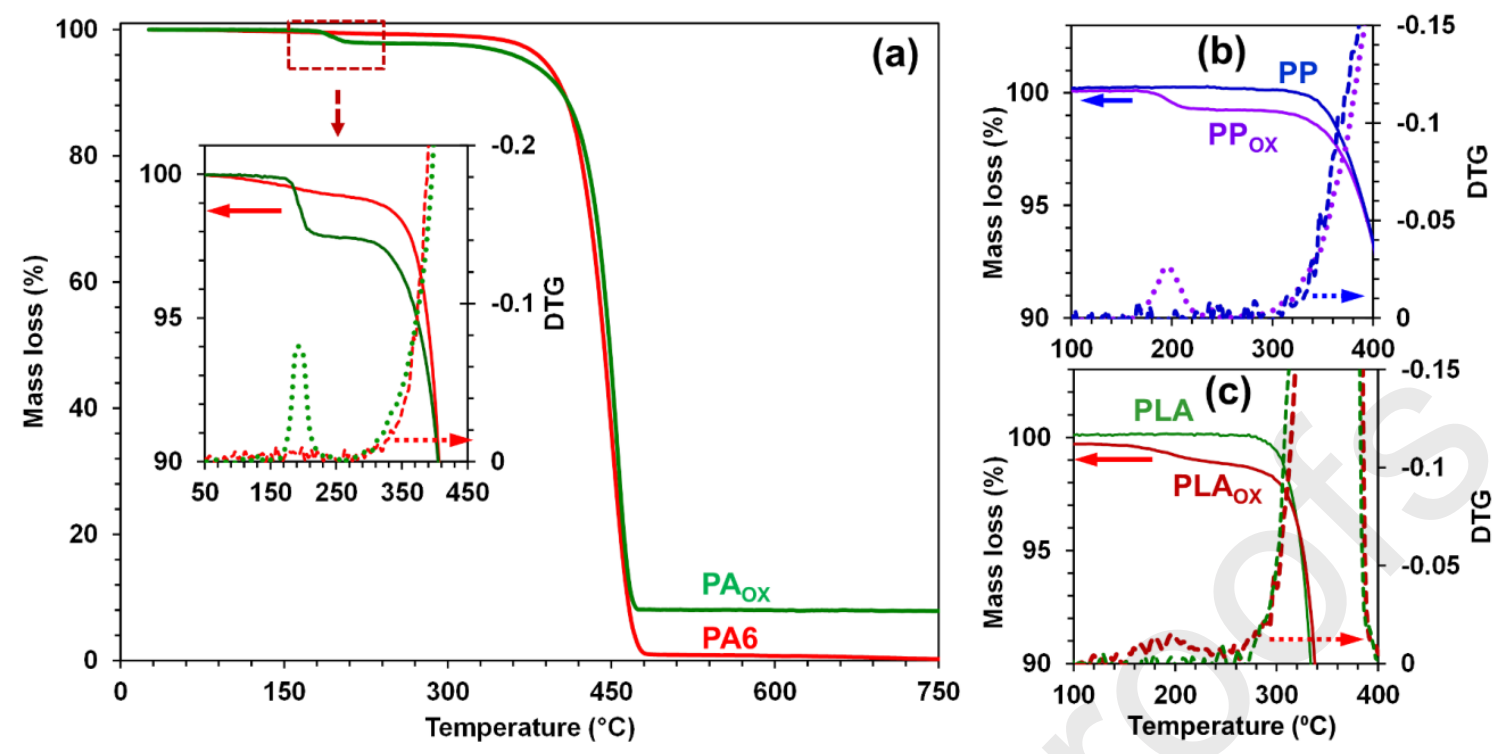

(d)

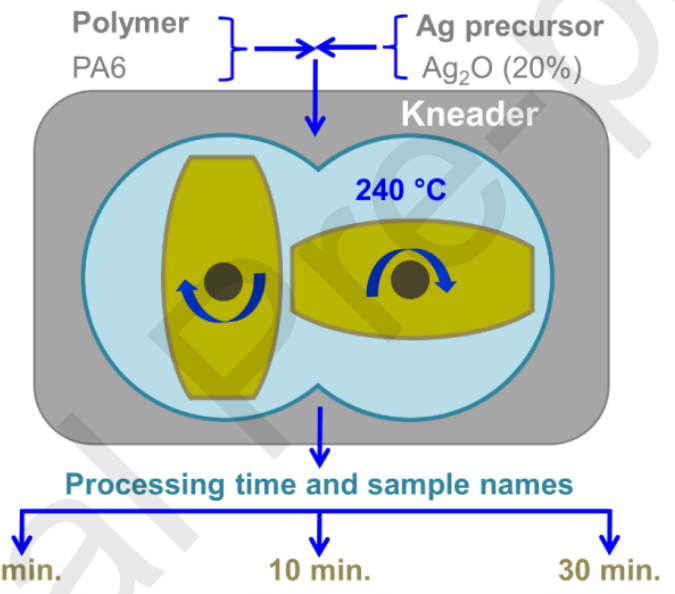

$\left(5 \mathrm{PA}_{200 x}\right)$

$\left(10 \mathrm{PA}_{200 x}\right)$

$\left(30 \mathrm{PA}_{200 \mathrm{x}}\right)$

Fig. 1. TGA curve showing (a) decomposition of PA6 in the absence (neat) and presence of 10 wt. $\% \mathrm{Ag}_{2} \mathrm{O}\left(\mathrm{PA}_{\mathrm{OX}}\right)$ under $\mathrm{N}_{2}$. The inset shows the enlarged view of the low-temperature region and corresponding derivative thermogravimetry (DTG curve) in dotted lines, highlights the sharp mass loss of $\sim 2 \%$ (at $175^{\circ} \mathrm{C}$ ) prior to the actual decomposition of PA6. (b), (c) Enlarged view of the TGA and DTG curve (dotted lines) showing the mass loss in the low-temperature region during decomposition of $\mathrm{PP}_{\mathrm{OX}}\left(\mathrm{PP}+10\right.$ wt.\% $\left.\mathrm{Ag}_{2} \mathrm{O}\right)$ and $\mathrm{PLA}_{\mathrm{OX}}\left(\mathrm{PLA}+10 \mathrm{wt} \% \mathrm{Ag}_{2} \mathrm{O}\right)$. TGA curve of pristine PP and PLA are shown for comparison. The onset of weight loss was observed at $165^{\circ} \mathrm{C}$ and $155^{\circ} \mathrm{C}$ for $\mathrm{PP}_{\mathrm{OX}}$ and $\mathrm{PLA}_{\mathrm{OX}}$ respectively. Full-scale TGA spectra can be found in Sec S2 of SI. (d) General scheme and sample nomenclature for AgNP composites prepared using $\operatorname{Ag}_{2} \mathrm{O}$ (20 wt.\%) and PA6 at $240{ }^{\circ} \mathrm{C}$ for different durations. The sample name 5PA $200 x$ indicates that, PA6 and 20 wt.\% $\mathrm{Ag}_{2} \mathrm{O}$ were melt-mixed (kneaded) for 5 min. 
Similar mass loss profile was observed when $\mathrm{Ag}_{2} \mathrm{O}-\mathrm{PP}$ mixture was analyzed in TGA. PP being a hydrophobic polymer, mass loss was in good agreement with the calculated value i.e. 0.7\% (Fig. 1b). The onset of mass loss in $\mathrm{Ag}_{2} \mathrm{O}$-PLA mixture started at a much lower temperature $\left(155^{\circ} \mathrm{C}\right)$. Similar observations in all the polymers confirmed that, the presence of polymers substantially decreased the thermal reduction temperature of $\mathrm{Ag}_{2} \mathrm{O}$, which is in agreement with mass loss observed during TGA of $\mathrm{Ag}_{2} \mathrm{O}$-polymer mixtures. To the best of our knowledge, such polymerassisted reduction of $\mathrm{Ag}$ precursors well below their decomposition temperature has never been reported in the literature.

\subsection{Processing time for AgNP formation}

Encouraged by the polymer-assisted low-temperature thermal reduction, melt-mixing (kneading) experiments were designed with higher $\mathrm{Ag}_{2} \mathrm{O}$ loading (20 wt.\%) using PA6 as a matrix, to determine the processing conditions for complete in-situ reduction of $\operatorname{Ag}_{2} \mathrm{O}$. Schematic representation of the process with nomenclature of the prepared samples are shown in Fig. 1d. Dynamics of mixing conditions during kneading can facilitate the reduction of $\mathrm{Ag}_{2} \mathrm{O}$ by creating new polymer metal-interface and thus rendering the whole reduction process faster than a static environment such as TGA. Therefore, a minimum processing time of 5 min was chosen during the kneading experiments, which was subsequently increased to $10 \mathrm{~min}$ and $30 \mathrm{~min}$ (Fig. 1d).

$\mathrm{UV}$-vis spectra of AgNP-polymer composites were recorded to assess the efficacy of solventless in-situ reduction process (Fig. 2a). For comparison, virgin PA6 and $\mathrm{Ag}_{2} \mathrm{O}$ were also analyzed. A diffused absorption band was observed in case of $\mathrm{Ag}_{2} \mathrm{O}$ powder due to presence of large particles. Whereas, AgNP-polymer composites (5PA $200 x$, 10PA $200 x$ and 30PA $200 x)$ displayed strong UV-vis absorption peak at $\sim 414 \mathrm{~nm}$, typical to Localized Surface Plasmon Resonance (LSPR) of nanosilver.[59, 60] No obvious shift in peak position was observed between 5 PA $\mathbf{A}_{200 x}, 10 P A_{200 x}(414$ 
$\mathrm{nm}$ ) indicating the formation of AgNPs with similar size. On the other hand, a minor positive shift in UV-vis absorption peak was observed in $\mathbf{3 0 P} \mathbf{A}_{\mathbf{2 0 0 x}}(418 \mathrm{~nm})$, which may arise due to formation of larger AgNPs due to longer processing time (30 min).[60] AgNP-PA6 composites were further analyzed via powder XRD to ascertain the degree of conversion of $\mathrm{Ag}_{2} \mathrm{O}$ to $\mathrm{Ag}^{0}$.
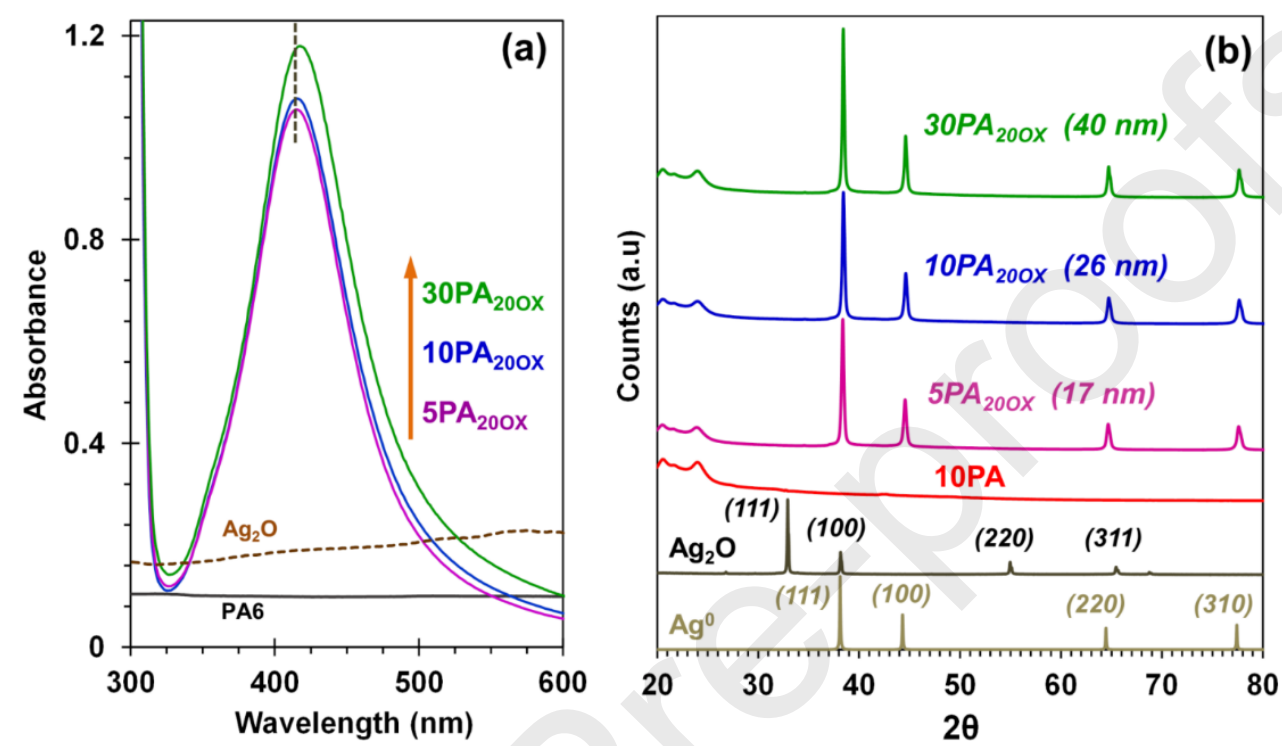

Fig. 2. (a) UV-vis absorption spectra of AgNP-PA6 composite $\left(\mathbf{5 P A _ { 2 0 0 x } , 1 0 P A _ { 2 0 0 x } , 3 0 P A _ { 2 0 0 x } )}\right.$ along with virgin PA6 and $\mathrm{Ag}_{2} \mathrm{O}$ powder. For UV-vis, hexafluoro-2-propanol was used as the solvent. (b) XRD patterns of $\mathrm{Ag}_{2} \mathrm{O}$ and AgNP-PA6 composites obtained after 5 min (5PA $\left.\mathbf{A}_{\mathbf{2 0 0 x}}\right), 10$ $\min \left(\mathbf{1 0 P A}_{200 x}\right)$ and $30 \mathrm{~min}\left(\mathbf{3 P P A}_{\mathbf{2 0 0 x}}\right)$ processing time respectively. The peak corresponding to 111 plane $\left(2 \theta=38.3^{\circ}\right)$ was used to estimate AgNP domain size (indicated in parentheses).

XRD patterns of AgNP composites (Fig. 2b) showed well-defined diffraction peaks at $2 \theta$ of $38.3^{\circ}$, $44.4^{\circ}, 64.6^{\circ}$ and $77.5^{\circ}$ assigned to (111), (200), (220), and (310) reflections of face-centered cubic $\mathrm{Ag}^{0}$ crystals respectively.[25, 37, 61] Absence of $\mathrm{Ag}_{2} \mathrm{O}$ diffraction peaks in all AgNP-PA6 composites confirmed the quick reduction of $\mathrm{Ag}_{2} \mathrm{O}$ (within $5 \mathrm{~min}$ ) under dynamic mixing condition. Domain size of AgNPs calculated from XRD patterns (Fig. 2b) was found to increase with the processing time. 

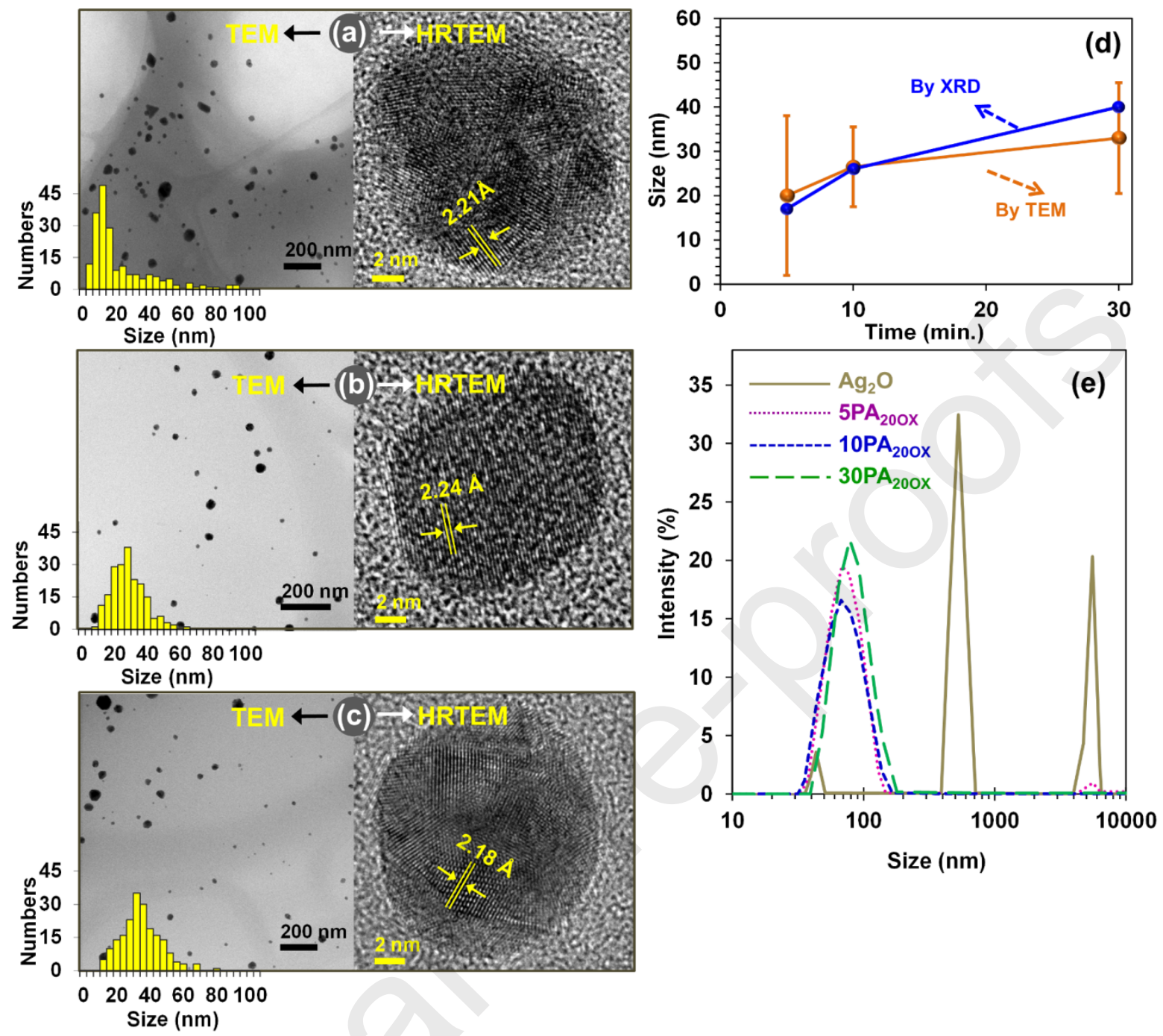

Size $(\mathrm{nm})$

Fig. 3. TEM and corresponding HRTEM image of (a) $5 \mathbf{P A}_{200 x}$, (b) $10 P \mathbf{A}_{200 x}$, (c) $30 P \mathbf{A}_{200 x}$ showing particle size and lattice plane distance in AgNPs along with particle size histogram superimposed on the TEM image of the respective sample. (d) Comparison of particle size determined by XRD and TEM analysis. (e) Intensity-average particle size of $\mathrm{Ag}_{2} \mathrm{O}, \mathbf{5 P A} \mathbf{2 0 0 x}$, 10PA $200 x$ and 30PA $200 x$ determined by DLS analysis.

A similar trend in AgNP size was also observed when composites were analyzed under TEM (Fig. 3a-c). TEM images of $\mathbf{5 P} \mathbf{A}_{\mathbf{2 0 0 x}}$ indicate the formation of AgNPs with a very broad size distribution, with a large population of NPs being of small size as evident from the histogram in Fig. 3a. On the subsequent increase in processing time to $10 \mathrm{~min}$ and $30 \mathrm{~min}$, an increase in average size was 
observed. Size uniformity was found to improve initially $\left(\mathbf{1 0 P} \mathbf{A}_{\mathbf{2 0 0 x}}\right)$, followed by an increase in non-uniformity (30PA $\mathbf{2 0 0 x}_{\text {20 }}$ ) as shown in TEM image and corresponding size histogram (Fig. 3b and c). Change in AgNP size and distribution with processing time (Fig. 3d) revealed that longer processing time $(10 \mathrm{~min})$ facilitates the growth of $\mathrm{AgNPs}$ both by addition of $\mathrm{Ag}^{0}$ atoms to $\mathrm{Ag}$ crystals and by merger of small particles. This led to a controlled growth of nanoparticles and narrowing of size distribution. Increasing the processing time further to $30 \mathrm{~min}$, a broadening of size distribution along with the increase in the size of the AgNPs was observed. It is thus believed that with longer processing time; AgNPs grow predominantly via merging of particles, demonstrating an uncontrolled growth pattern. Lattice plane distances determined from HRTEM analysis of all composites (Fig. 3 a-c) was found to be around $2.2 \AA$, which is in agreement with the literature data for AgNPs.[15, 31] During HRTEM analysis, large population of NPs showed multifaceted structure, supporting the argument of AgNP growth in polymer melt via merging of smaller NPs.

DLS particle size of $\mathrm{Ag}_{2} \mathrm{O}$ powder and AgNPs composites was determined to monitor the evolution of AgNP with processing time. AgNP-PA6 composites solution in hexafluoro-2-propanol was used for DLS analysis (Fig. 3e). Interestingly, the multimodal distribution of particles observed in case of $\mathrm{Ag}_{2} \mathrm{O}$ powder transformed to a bimodal distribution just after 5 min melt-kneading (5PA $200 x$ ). Increasing the processing time further $\left(\mathbf{1 0 P A}_{\mathbf{2 0 0 x}}, \mathbf{3 0 P A}_{\mathbf{2 0 0 x}}\right)$ resulted in AgNPs with unimodal size distribution. However, in all these composites the intensity-average particle size (Table S1) remained higher than the particle size obtained from XRD and TEM analysis. Non-linear variation in scattering intensity due to presence of a few larger particles or aggregates and polymer chains around AgNPs can lead to overestimation of intensity-average nanoparticle size.[62, 63] On the contrary, number-average size corresponding to isolated AgNPs was observed to be close to the AgNP size obtained from XRD and TEM analysis (Table S1). Overall, an increased in DLS size and distribution was also observed when processing time was increased to $30 \mathrm{~min}$ (Table S1). This 
is in agreement with TEM and XRD analysis and confirms the uncontrolled growth of AgNPs during longer processing time. AgNP distribution in the PA6 matrix was observed by EDX mapping of AgNP-PA6 composites (Fig. S6-S8). In the case of 5PA $\mathbf{A}_{\mathbf{2 0 0 x}}$, a non-uniform particle distribution in the PA6 matrix was observed along with the presence of large clusters (Fig. S6). Increasing the kneading time to 10 and 30 min improved the AgNP distribution significantly and prevented the cluster formation (Fig. S7 and S8).

\subsection{Changes in macromolecular characteristics of PA6}

FTIR analysis was carried out on the nanocomposites to determine the chemical changes in PA6 matrix after in-situ synthesis of AgNP (Fig. 4a). For comparison, virgin PA6 samples were processed at the same temperature and duration (10 and $30 \mathrm{~min}$ ) as that for AgNP-PA6 composites (Table 1). The FTIR spectra of samples were normalized according to the characteristic band at $1465 \mathrm{~cm}^{-1}$. The $\mathrm{N}-\mathrm{H}$ deformation along with $\mathrm{C}-\mathrm{N}$ stretching appears at $1540 \mathrm{~cm}^{-1}$ and the band at $1650 \mathrm{~cm}^{-1}$ represents the characteristic of $\mathrm{C}-\mathrm{O}$ stretching vibrations of amide group. No significant difference in FTIR spectra of different PA6 samples was observed.
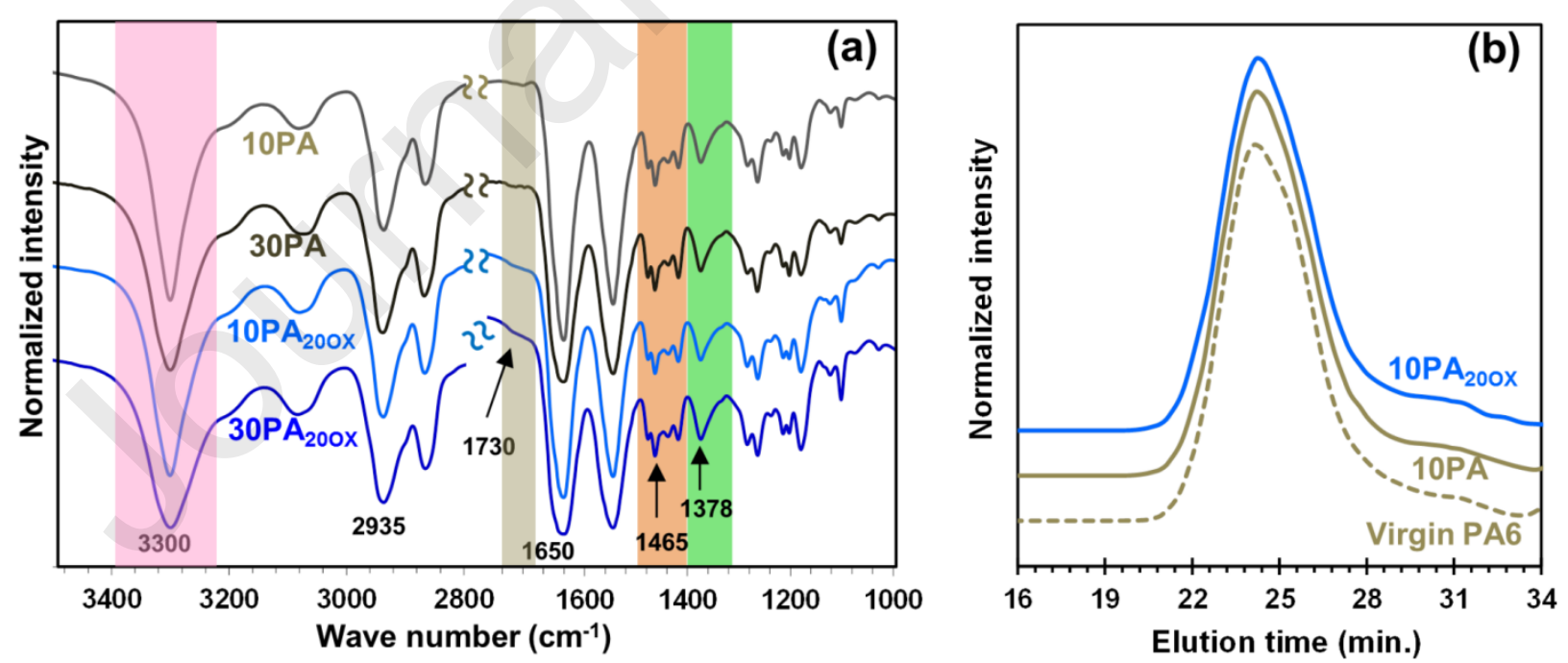

Fig. 4. (a) Normalized FTIR spectra of 10PA, 30PA, 10PA $\mathbf{A}_{200 x}$ and $30 P A_{200 x}$ respectively. 10PA and 30PA samples were processed without $\mathrm{Ag}_{2} \mathrm{O}$ for $10 \mathrm{~min}$ and $30 \mathrm{~min}$ respectively. (b) GPC elution traces of virgin PA6, PA6 kneaded for $10 \min (\mathbf{1 0 P A})$ and 10PA200x. 
Table 2. Macromolecular characteristics of virgin and melt-kneaded PA6 determined by GPC.

\begin{tabular}{ccc}
\hline Sample & Mn (g/mol) & Mw/Mn (PDI) \\
\hline PA6 (virgin) & $1.62 \times 10^{4}$ & 1.93 \\
10PA & $1.60 \times 10^{4}$ & 1.95 \\
10PA $200 x^{2}$ & $1.55 \times 10^{4}$ & 2.0 \\
\hline
\end{tabular}

To detect minor changes in PA6 matrix during in-situ reduction, intensity ratios of different peaks were considered. Careful analysis showed that, intensity ratio between $3300 \mathrm{~cm}^{-1}(\mathrm{~N}-\mathrm{H}$ band) and $1465 \mathrm{~cm}^{-1}\left(\mathrm{I}_{3300}: \mathrm{I}_{1465}\right)$ decreased with increase in the kneading time from $10 \mathrm{~min}$ to $30 \mathrm{~min}$ (Table S2). However, presence of $\mathrm{Ag}_{2} \mathrm{O}$ during the processing of polyamide has no significant effect on $\mathrm{I}_{3300}: \mathrm{I}_{1465}$ (Table $\mathrm{S} 2$ ). Such changes can be attributed to chain scission in PA6 due to long processing time (30 min.), which was further confirmed by the reduced intensity of band corresponding to C$\mathrm{O}$ stretching of amide $\left(1650 \mathrm{~cm}^{-1}\right)$. A broadening of the band at $1650 \mathrm{~cm}^{-1}$ and absence of any noticeable changes in the $\mathrm{C}=\mathrm{O}$ region $\left(1730 \mathrm{~cm}^{-1}\right)$ indicates the formation of $-\mathrm{CHO}$ and $-\mathrm{NH}_{2}$ chain ends during to chain scission.[64, 65] Interestingly, $-\mathrm{CH}_{2}$ wagging vibrations at $1378 \mathrm{~cm}^{-1}$ coinciding with the band of $-\mathrm{NO}_{2}$ found to increase in case of $10 P \mathbf{A}_{200 x}$ and $30 P A_{200 x}$ as confirmed by $\mathrm{I}_{1378}: \mathrm{I}_{1465}$ ratio (Fig. $4 \mathrm{a}$ and Table $\mathrm{S} 2$ ). This indicates the oxidation of $-\mathrm{NH}_{2}$ chain ends to $\mathrm{NO}_{2} \cdot[51,52]$ From FTIR analysis it is clear that no significant chemical changes or degradation of PA6 takes place during in-situ AgNP synthesis. GPC analysis also confirmed such observations as a very minor increase in the low molecular weight fraction was observed in case of 10PA $\mathbf{2 0 0 x}$ compared to virgin PA6 and 10PA (Fig. 4b and Table 2). TGA analysis of 10PA200x showed similar degradation profile as that of virgin PA6 with no detectable effect of AgNPs on PA6 matrix (Figure S9). This also confirms that minimal chemical changes happen to the PA6 matrix during in-situ AgNP synthesis.

A mild reducing environment of the polymer melt (presence of functional groups such as $\mathrm{CH}_{2}$ and $\mathrm{NH}_{2}$ ) contribute towards the partial reduction of $\mathrm{Ag}_{2} \mathrm{O}$ to $\mathrm{Ag}^{0}$, which can be called as the induction 
period (Fig. 5b). Later, $\mathrm{Ag}^{0}$ formed during induction phase starts to condense and polymer-assisted thermal reduction of $\mathrm{Ag}_{2} \mathrm{O}$ enters the autocatalytic phase (Fig. 5c).[45, 46] Reducing environment created due to the release of $\mathrm{H}_{2}$ during melt-kneading can lower the activation energy $\left(E_{a}\right)$ of the thermal reduction of $\mathrm{Ag}_{2} \mathrm{O}$ significantly.[46-48] As a result, a complete reduction of $\mathrm{Ag}_{2} \mathrm{O}$ was achieved within 5 minutes at a much lower temperature, without causing any significant damage to the PA matrix. From TEM and FTIR analysis, it is clear that $10 \mathrm{~min}$ processing time is suitable for AgNP-PA6 composite preparation without the risk of unnecessary polymer degradation. Hence, all other AgNP-polymer composites were prepared with 10 min processing time.

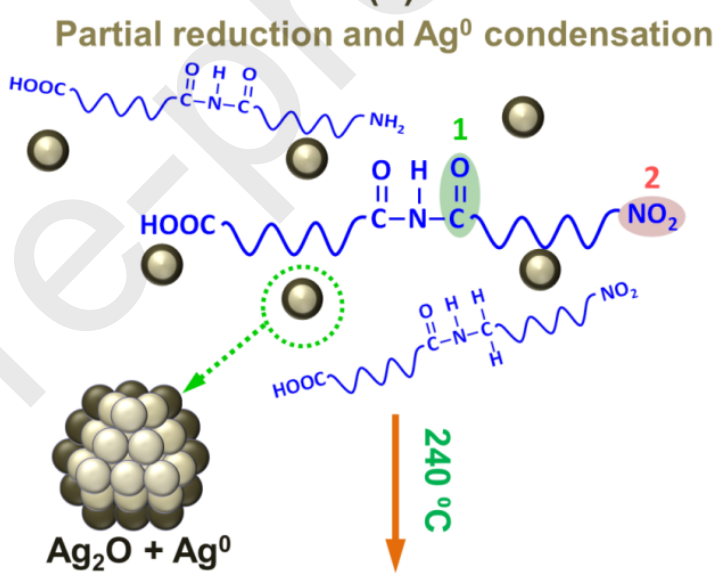

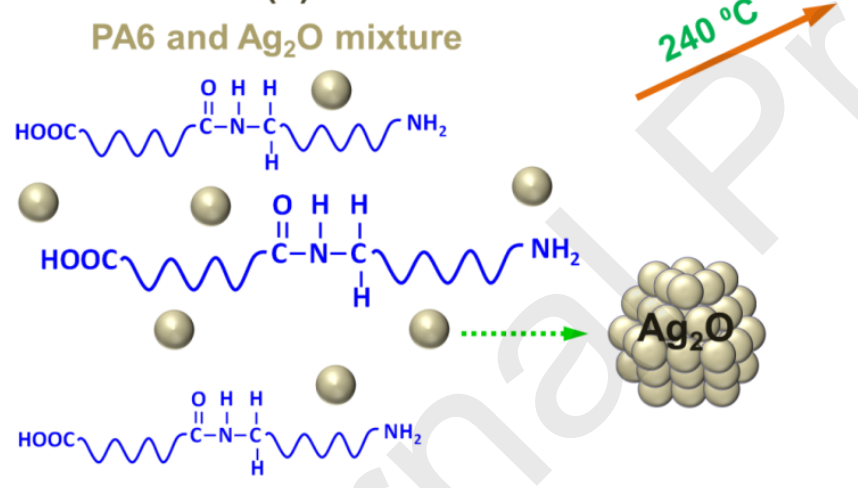

(a) (c)

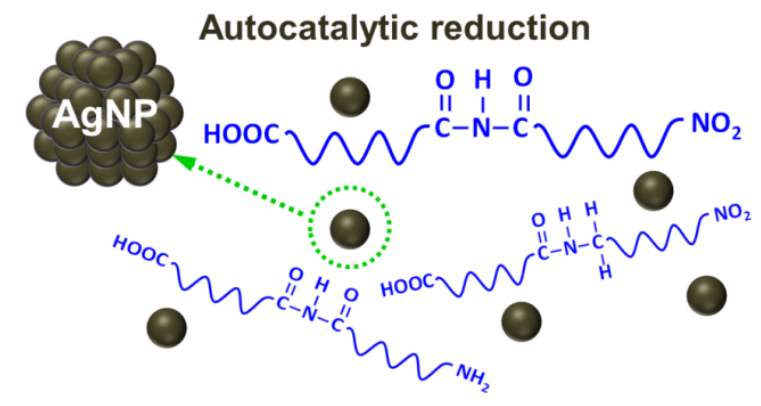

Fig. 5. Simplified schematic representation showing different phases of $\mathrm{Ag}_{2} \mathrm{O}$ reduction in presence of PA6. (a) PA6- $\mathrm{Ag}_{2} \mathrm{O}$ mixture, (b) oxidation of $\mathrm{PA} 6$ chains at $\mathrm{CH}_{2}$ (1) and $\mathrm{NH}_{2}$ (2) without chain scission [51,52] along with partial reduction of $\mathrm{Ag}_{2} \mathrm{O}$ and condensation of $\mathrm{Ag}^{0}$ (induction phase) (c) autocatalytic reduction of remaining $\mathrm{Ag}_{2} \mathrm{O}$. For simplicity, other possible oxidation and chain scission which contribute to reduction of $\mathrm{Ag}_{2} \mathrm{O}$ are not shown here. 


\subsection{AgNP composites using PLA and PP}

The reduction of $\mathrm{Ag}_{2} \mathrm{O}$ in molten PA6 was further extended to solventless AgNP synthesis within other polymer matrices, i.e. PLA and PP. Keeping all other processing conditions same, kneading temperature was maintained at $200^{\circ} \mathrm{C}$ and $165^{\circ} \mathrm{C}$ for PP and PLA respectively. UV-vis analysis of 10PLA $\mathbf{A}_{200 x}$ showed the presence of a strong LSPR (Fig. 6a), indicating significant reduction of $\mathrm{Ag}_{2} \mathrm{O}$ to AgNPs even at a low temperature in the presence of PLA. In case of 10PLA $200 x$ intensityaverage $(54.6 \mathrm{~nm})$ and number-average $(27.3 \mathrm{~nm})$ size determined by DLS were lower compared to the particle size of AgNP-PA6 composites.
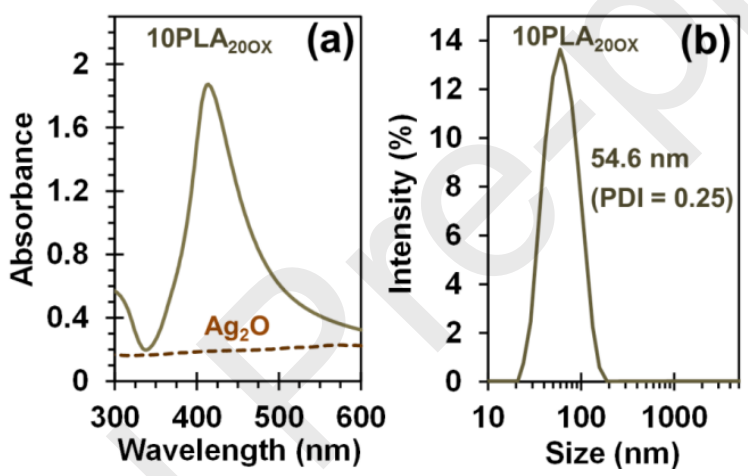

Fig. 6. (a) UV-vis absorption spectra of $\mathrm{Ag}_{2} \mathrm{O}$ and 10PLA $\mathbf{A}_{200 x}$, (b) Intensity-average DLS particle size of 10PLA $\mathbf{A}_{200 x}$. For UV-vis and DLS analysis hexafluoro-2-propanol was used as the solvent.

Using the XRD pattern of 10PLA $\mathbf{A}_{200 x}$ and 10PLA samples shown in Fig. 7a, a Rietveld-base quantitative phase analysis was attempted to determine the $\mathrm{Ag}_{2} \mathrm{O}$ reduction efficiency. In this case, some ambiguity in clearly estimating the $\mathrm{Ag}^{0}$ content of the composite was encountered due to contribution from broad peak of underlying polymer matrix and a very low intensity of unreduced $\mathrm{Ag}_{2} \mathrm{O}$ peak. Based on this analysis, a conservative estimation of $95 \pm 3 \%$ mass fraction of $\mathrm{Ag}^{0}$ in the 10PLA $\mathbf{A}_{200 x}$ was made. This confirms that nearly complete reduction of $\mathrm{Ag}_{2} \mathrm{O}$ was achieved within 10 min in the presence of molten PLA $\left(165^{\circ} \mathrm{C}, \mathbf{1 0 P L A} \mathbf{A}_{\mathbf{2 0 0 x}}\right)$. AgNP size in 10PLA $\mathbf{A}_{\mathbf{2 0 0 x}}$ determined by XRD analysis was found to be $28 \pm 2 \mathrm{~nm}$, which is slightly higher than the average particle size obtained by TEM 
analysis $(18 \pm 6 \mathrm{~nm})$. Lattice plane distance of $2.2 \AA$ determined by HRTEM analysis of 10PLA $\mathbf{A}_{\mathbf{2 0 0 x}}$ is in good agreement with metallic AgNPs (Fig. 7b).[15]

Analysis of FTIR spectra of PLA samples processed without $\mathrm{Ag}_{2} \mathrm{O}(\mathbf{1 0 P L A})$ and in the presence of $\mathrm{Ag}_{2} \mathrm{O}\left(10 \mathrm{PLA} \mathbf{A}_{200 x}\right)$ confirmed no significant chemical difference between PLA matrices (Fig. 7c). Bands at $1754 \mathrm{~cm}^{-1}, 1450 \mathrm{~cm}^{-1}$ can be attributed to $-\mathrm{C}=\mathrm{O}$ stretch of ester group and $-\mathrm{CH}_{3}$ bending vibrations respectively.[20, 66] Band at $1383 \mathrm{~cm}^{-1}$ is due to symmetric deformation of $-\mathrm{CH}_{3}$. The presence of a band corresponding to $-\mathrm{OH}\left(3510 \mathrm{~cm}^{-1}\right)$ was observed in both samples (Fig. S10), suggesting chain scission of PLA during thermal processing with the formation of - $\mathrm{COOH}$ chain ends.[66] Though the intensity at $3510 \mathrm{~cm}^{-1}$ was same in both 10PLA and 10PLA $\mathbf{A}_{200 x}$, the intensity of the peak corresponding to $-\mathrm{C}=\mathrm{O}\left(1754 \mathrm{~cm}^{-1}\right)$ was lower and broader in case of 10PLA compared to 10PLA. When the peak area ratio of the bands at $1754 \mathrm{~cm}^{-1}$ and $1450 \mathrm{~cm}^{-1}\left(\mathrm{~A}_{1754} / \mathrm{A}_{1450}\right)$ in 10PLA $A_{200 x}$ and 10PLA were compared, no change in the ratio was observed. This suggests similar amounts of PLA chain degradation in both samples and broadening of the band at $1754 \mathrm{~cm}^{-1}$ in 10PLA $\mathbf{A}_{200 x}$ can be explained by the interaction of $-\mathrm{C}=\mathrm{O}$ AgNPs. Bands of amorphous and crystalline phases of PLA were observed at 867 and $753 \mathrm{~cm}^{-1}$ respectively.[20] In FTIR spectra of 10PLA $\mathbf{A}_{200 x}$ no noticeable changes in these bands indicate any significant impact of in-situ AgNP synthesis on the crystallinity of PLA.
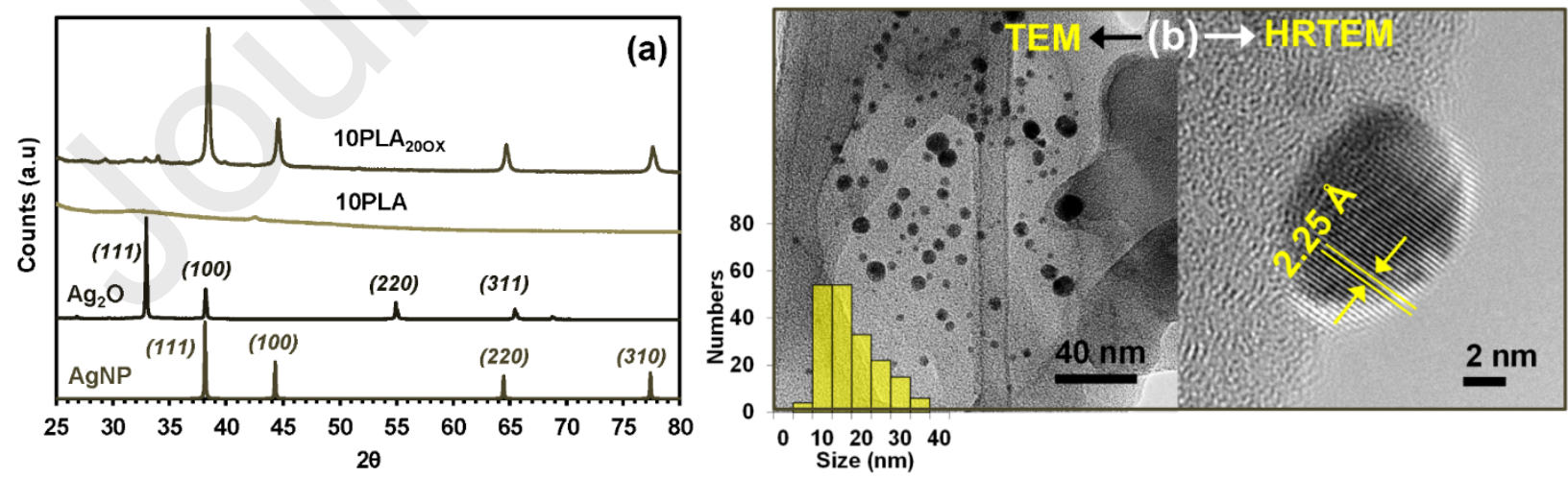


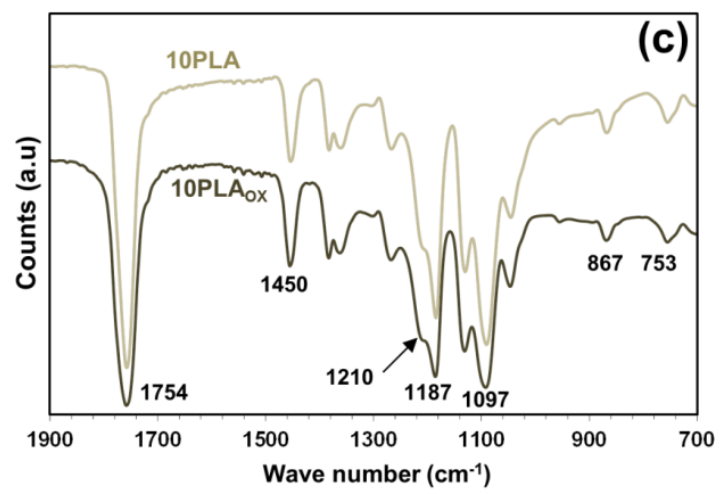

Fig. 7. (a) XRD pattern of $\mathrm{Ag}_{2} \mathrm{O}$ and $10 \mathrm{PLA} \mathbf{A}_{200 x}$ showing a nearly complete $(95 \pm 3 \%)$ reduction of $\mathrm{Ag}_{2} \mathrm{O}$ to $\mathrm{Ag}^{0}$ after 10 min melt-mixing with the presence of a very small fraction of unreduced $\mathrm{Ag}_{2} \mathrm{O}$. (b) TEM and HRTEM of 10PLA $\mathbf{A}_{200 x}$ showing particle size distribution and lattice plane distance respectively. (c) FTIR spectra of 10PLA (without $\mathrm{Ag}_{2} \mathrm{O}$ ) and 10PLA $\mathbf{A}_{200 x}$.

When PP was used as the matrix $\left(\mathbf{1 0 P P}_{\mathbf{2 0 0 x}}\right), \sim 60.0 \%$ of $\mathrm{Ag}_{2} \mathrm{O}$ was reduced to $\mathrm{Ag}^{0}$ even at a processing temperature of $200{ }^{\circ} \mathrm{C}$ (Fig. 8a). TEM analysis (Fig. 8b) revealed the presence of two different populations of AgNPs in $\mathbf{1 0 P P}_{\mathbf{2 0 0 x}}$ composite. Lattice plane distance in the case of small AgNPs in the composite was found to be of $2.2 \AA$ (Fig. 8b), which is in agreement with that of the metallic AgNPs. When large clusters of particles were examined under HRTEM, lattice plane distance corresponding to $\mathrm{Ag}_{2} \mathrm{O}$ (2.6 $\AA$ ) was observed (Fig. S11 and S12).[67] Presence of small AgNPs and clusters of unreduced $\mathrm{Ag}_{2} \mathrm{O}$ highlights the influence of $\mathrm{Ag}$ precursor-polymer incompatibility on the reduction of the precursor.

For better understanding of the role of precursor-polymer compatibility on reduction of $\operatorname{Ag}_{2} \mathrm{O}$, surface free energy of polymer melt and the corresponding $\mathrm{Ag}_{2} \mathrm{O}$ conversion to $\mathrm{Ag}^{0}$ are plotted in Fig. 8c. It can be seen that, surface energy of polymer melt influence the in-situ reduction $\operatorname{~of~} \operatorname{Ag}_{2} \mathrm{O}$ significantly. Polymer melts with higher surface energy (PA6) favor wetting of $\mathrm{Ag}_{2} \mathrm{O}$ during the initial phase of mixing. This leads to the breaking of $\mathrm{Ag}_{2} \mathrm{O}$ clusters to smaller particles with uniform dispersion within the molten polymer and smaller particles are likely to be reduced faster than large particles, owing to their high surface area. This was confirmed by comparing the $\mathrm{Ag}_{2} \mathrm{O}$ reduction in PA6 and PLA melt. Complete reduction of $\mathrm{Ag}_{2} \mathrm{O}$ within 5 min in PA6 (Sec. 3.1) compared to 95 
$\pm 3 \%$ reduction in case of PLA after 10 min processing highlights the better wetting of $\mathrm{Ag}_{2} \mathrm{O}$ in PA6 melt, owing to its higher surface energy (Fig. 8c).[68-70]
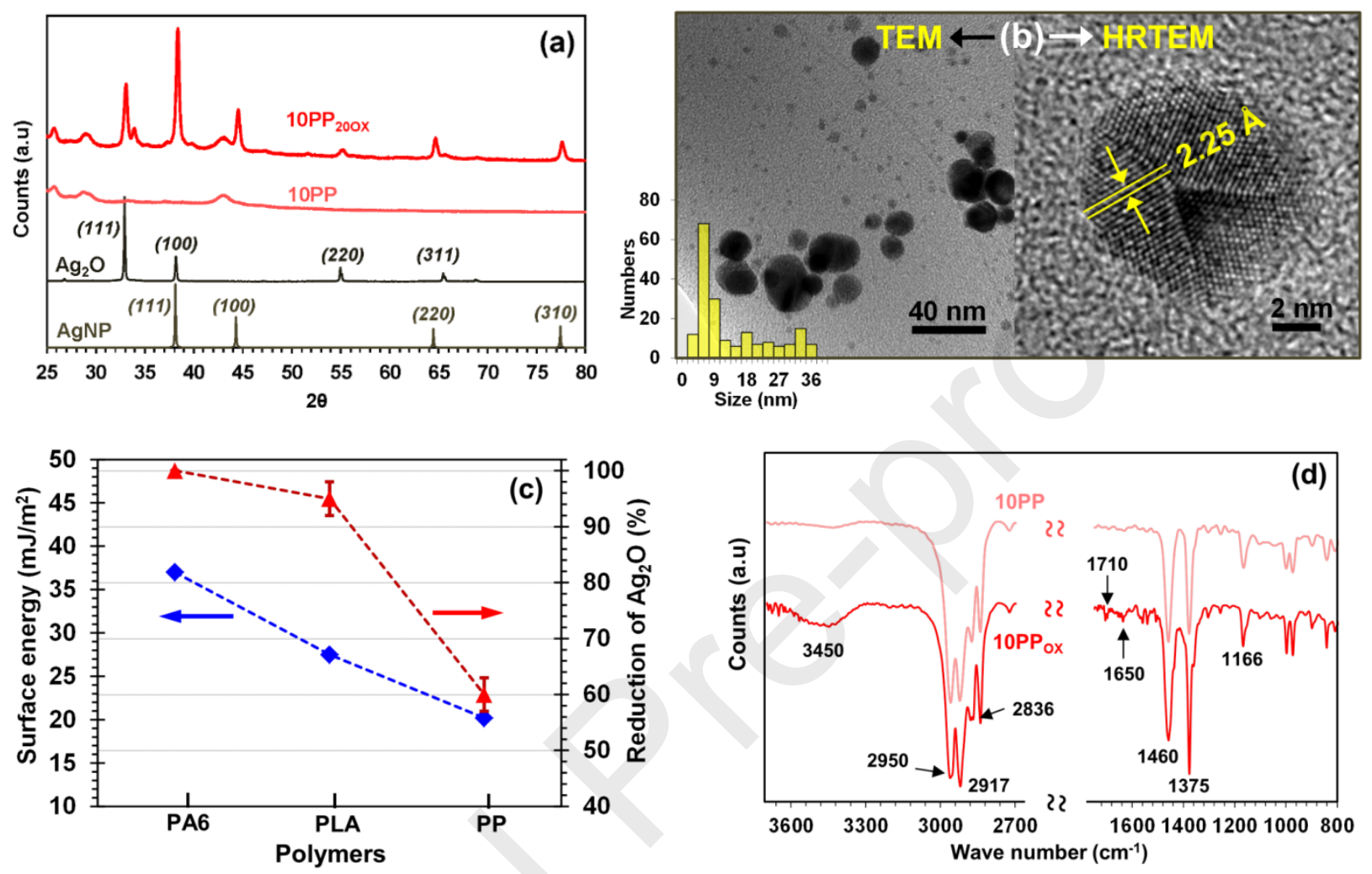

Fig. 8. (a) XRD pattern of $\mathbf{1 O P P}_{\mathbf{2 0 0 x}}$ showing the presence of both metallic silver $\left(\mathrm{Ag}^{0}\right)$ and unreduced silver $\left(\mathrm{Ag}_{2} \mathrm{O}\right)$. 10PP $\mathbf{P O O x}_{\mathbf{2 0}}$ shows the presence of a significant quantity of unreduced $\operatorname{Ag}_{2} \mathrm{O}$ ( $\sim 40 \%$ of initial $\mathrm{Ag}_{2} \mathrm{O}$ ) (b) TEM and HRTEM of $\mathbf{1 0 P P _ { 2 0 0 x }}$ showing particle size distribution and lattice distance respectively. (c) Showing the influence of surface free energy of PA6, PLA and PP melt on in-situ reduction of $\mathrm{Ag}_{2} \mathrm{O}$. Surface free energy values for all the polymers were taken from the literature. (d) FTIR spectra of PP processed for 10 min with $20 \% \mathrm{Ag}_{2} \mathrm{O}\left(\mathbf{1 0 P P} \mathbf{2 0 0 x}_{\text {) }}\right.$ and without $\mathrm{Ag}_{2} \mathrm{O}$ (10PP).

Unlike PA6 and PLA, PP has no polar groups and has relatively lower surface energy.[70-72] This leads to poor wetting of $\mathrm{Ag}_{2} \mathrm{O}$ in the polymer melt and limits the distribution of $\mathrm{Ag}_{2} \mathrm{O}$ clusters. As a result, incomplete reduction (60\%) of $\mathrm{Ag}_{2} \mathrm{O}$ clusters was observed in $\mathbf{1 0 P P _ { 2 0 0 x }}$ (Fig. 8a, S11 and 12). To determine the reduction mechanism of $\mathrm{Ag}_{2} \mathrm{O}$ in PP, FTIR analysis was carried out and presented in Fig. 8d. Characteristic bands of PP were clearly identified at $2950 \mathrm{~cm}^{-1}, 2917 \mathrm{~cm}^{-1}$ and 
$2836 \mathrm{~cm}^{-1}$ which can be assigned to $-\mathrm{CH}_{3}$ asymmetric vibration $-\mathrm{CH}$ stretch, and $-\mathrm{CH}_{2}$ symmetric vibration respectively. Bands at $1460 \mathrm{~cm}^{-1}$ and $1375 \mathrm{~cm}^{-1}$ are due to $-\mathrm{CH}_{3}$ asymmetric and symmetric bending respectively. Careful analysis in the region from $2760 \mathrm{~cm}^{-1}$ to $3780 \mathrm{~cm}^{-1}$ revealed the changes taking place in PP. In the FTIR spectra of $\mathbf{1 0 P P} \mathbf{P o x}_{\mathbf{2 0 0}}$, decrease in the intensity of $-\mathrm{CH}_{3}\left(2950 \mathrm{~cm}^{-1}\right)$ and $-\mathrm{CH}$ band $\left(2917 \mathrm{~cm}^{-1}\right)$ with respect to $-\mathrm{CH}_{2}\left(2836 \mathrm{~cm}^{-1}\right)$ indicates the oxidation of PP chain to form in chain ketone.[73, 74] Hydrogen abstracted during this oxidation step can be utilized to reduce $\mathrm{Ag}_{2} \mathrm{O}$ without leading to chain scission. Apart from these changes, two new bands appeared in spectra of $\mathbf{1 0 P P}_{\mathbf{2 0 0 x}}$ at $1650 \mathrm{~cm}^{-1}$ and $1710 \mathrm{~cm}^{-1}$, which can be assigned to $-\mathrm{C}=\mathrm{C}-$ and $-\mathrm{C}=\mathrm{O}$ respectively. A broad absorption band at $3450 \mathrm{~cm}^{-1}$ became more intense in case of $\mathbf{1 0 P P}_{\mathbf{2 0 0 x}}$, possibly due to the presence of $-\mathrm{OH}$ as a result of residual hydroperoxides, which act as precursors for small molecular weight compounds including aldehyde and alcohols during melt-mixing of PP.[50, 75] It is worth mentioning here that the presence of alcohols and aldehydes at elevated temperature also helps to reduce $\operatorname{Ag}_{2} \mathrm{O}$ to metallic $\operatorname{Ag}^{0} \cdot[61,76,77]$

\subsection{AgNP-PA6 composites using alternative silver precursors}

The efficacy of this solventless in-situ composite preparation method was investigated using alternative precursors such as $\mathrm{Ag}_{2} \mathrm{CO}_{3}$ and $\mathrm{C}_{16} \mathrm{H}_{31} \mathrm{O}_{2} \mathrm{Ag}$. PA6 was used as the polymer matrix with $10 \mathrm{wt} . \%$ precursor loading at a processing temperature of $240{ }^{\circ} \mathrm{C}$ and duration of 10 minutes. For comparison, a sample was also prepared with 10 wt.\% $\operatorname{Ag}_{2} \mathrm{O}$. As confirmed by XRD analysis (Fig. 9), a complete reduction of all precursors was achieved with the employed processing conditions. AgNP domain size obtained using $\mathrm{Ag}_{2} \mathrm{CO}_{3}\left(\mathbf{1 0 P A} \mathbf{A}_{10 \mathrm{CAR}}\right)$ was $\sim 27 \mathrm{~nm}$, which is similar to that of

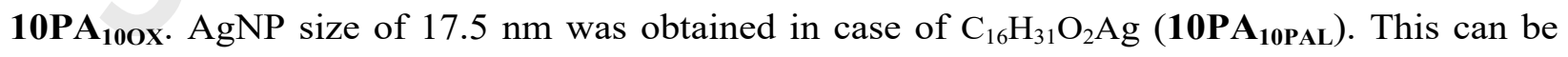
attributed to the very low silver content of $\mathrm{C}_{16} \mathrm{H}_{31} \mathrm{O}_{2} \mathrm{Ag}$, compared to other precursors. 
After synthesizing series of AgNP-polymer composites via a polymer assisted single step reduction technique, it was confirmed that silver nanoparticles can be synthesized in-situ at a much lower temperature $\left(165^{\circ} \mathrm{C}\right)$ compared to the actual decomposition temperature of $\mathrm{Ag}_{2} \mathrm{O}\left(375^{\circ} \mathrm{C}\right.$, Fig S2). It was observed that polymer melt surface energy plays a crucial role for successful in-situ reduction of silver precursor as compared to the processing temperature. This technique avoids solvents and energy-consuming steps typically involved in AgNP-polymer composite preparation methods (Table 3 ). In contrast to single step method reported in literature, $[23,42,43]$ polymer assisted single step reduction technique (Table 3, current Work), eliminates the risk of accumulating decomposition products of silver precursors. As a result, silver loading up to $18 \%$ can be achieved without altering the macromolecular characteristics of the polymer matrix. Whereas previous reported method could only achieve $\sim 2 \mathrm{wt} . \%$ of silver in the composite.

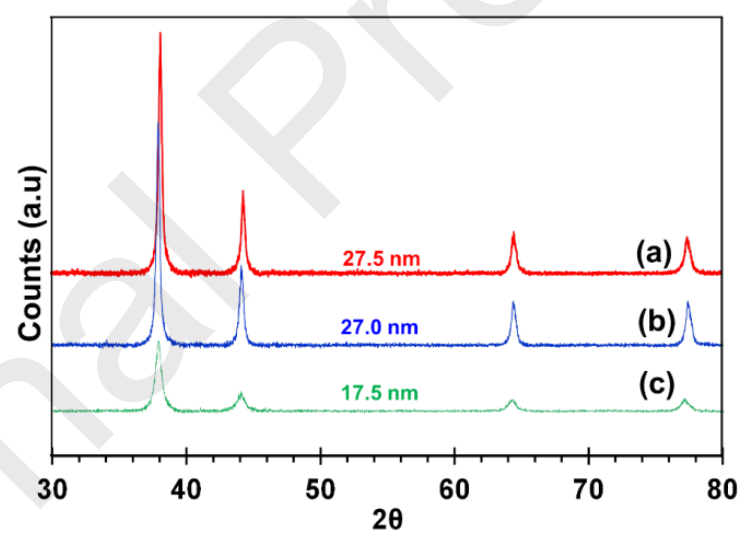

Fig. 9. XRD pattern and corresponding domain size of AgNP synthesized using PA6 as the matrix with 10 wt.\% loading of (a) $\mathrm{Ag}_{2} \mathrm{O}$, (b) $\mathrm{Ag}_{2} \mathrm{CO}_{3}$ and (c) silver palmitate $\left(\mathrm{C}_{16} \mathrm{H}_{31} \mathrm{O}_{2} \mathrm{Ag}\right.$ ). 
Table 3. Comparison of AgNP composite preparation techniques.

\begin{tabular}{|c|c|c|c|c|c|}
\hline Matrix & Ag source & Process & Temp. $\left({ }^{\circ} \mathrm{C}\right)$ & Time (h) & Ref. \\
\hline Polypropylene & AgNP & Melt mixing & 250 & - & {$[17]$} \\
\hline $\begin{array}{l}\text { Polyethylene, PLA, } \\
\text { Polyethyleneimine }\end{array}$ & AgNP & Solution casting & - & - & {$[18-21]$} \\
\hline \multicolumn{6}{|c|}{ In-situ reduction methods } \\
\hline $\begin{array}{c}\text { PVA } \\
\text { Poly(cardanyl } \\
\text { acrylate) }\end{array}$ & $\begin{array}{c}\mathrm{AgNO}_{3} \\
\mathrm{C}_{7} \mathrm{H}_{6} \mathrm{AgO}_{2}\end{array}$ & $\begin{array}{l}\text { Reduction by } \\
\text { oxidation of } \\
\text { polymer }\end{array}$ & 50-100 & $1 \& 24$ & $\begin{array}{c}{[27,34]} \\
{[26]}\end{array}$ \\
\hline Modified chitosan & $\mathrm{AgNO}_{3}$ & & & $0.5-1$ & {$[31-33]$} \\
\hline Polyimides & $\mathrm{AgNO}_{3}$ & $\begin{array}{l}\text { Thermal } \\
\text { reduction }\end{array}$ & 250 & 13 & {$[29,35-37]$} \\
\hline Polyacrylonitrile & $\mathrm{AgNO}_{3}$ & $\begin{array}{l}\text { Photochemical } \\
\text { reduction }\end{array}$ & RT & 0.5 & {$[38]$} \\
\hline Epoxy & $\mathrm{AgOCOCF}_{3}$ & & & - & {$[39,40]$} \\
\hline $\begin{array}{c}\text { Nylon } 6 \\
\text { Thermoplastic PU }\end{array}$ & $\mathrm{AgC}_{2} \mathrm{H}_{3} \mathrm{O}_{2}$ & $\begin{array}{l}\text { Thermal } \\
\text { reduction }\end{array}$ & $\begin{array}{l}230 \\
200\end{array}$ & - & $\begin{array}{c}{[23,42]} \\
{[43]}\end{array}$ \\
\hline Nylon 6, PLA, PP & $\begin{array}{c}\mathrm{Ag}_{2} \mathrm{O} \\
\mathrm{Ag}_{2} \mathrm{CO}_{3}, \\
\mathrm{C}_{16} \mathrm{H}_{31} \mathrm{O}_{2} \mathrm{Ag}\end{array}$ & $\begin{array}{l}\text { Polymer assisted } \\
\text { reduction by } \\
\text { melt mixing }\end{array}$ & $\begin{array}{l}240,200 \\
165\end{array}$ & $5-30 \mathrm{~min}$ & $\begin{array}{c}\text { Current } \\
\text { work }\end{array}$ \\
\hline
\end{tabular}

\subsection{Ag release and antimicrobial activity of $A g N P-P A 6$ composite.}

Antimicrobial activity of nano-scaled silver in polymer matrices is well established and such materials are used to prepare composites for water disinfection, air purification, food and medical packaging. [8, 78, 79] However, significant Ag release from these composites is highly undesirable due to health safety regulations. Therefore, AgNP-PA6 nanocomposites films with different silver content was prepared (sec. S7) and silver release from these films were studied. Prior to release study actual film thickness was determined by SEM (Fig. S13) and it was in in good agreement with the calculated film thickness $(11 \mu \mathrm{m})$. Actual silver content of the composite films was 
confirmed by ICP-OES analysis and mentioned in Table S3. Composite films showed an increase in accumulated silver content in the medium (Fig. 10a, b) with a faster release kinetics until to 24 hours, followed by a slower release profile. Interestingly, linear relationship between silver loading and its release (Fig. 10b) highlights the uniform distribution of AgNPs in the polymer matrix. Moreover, such linear relationship allows the tuning of the silver release according to the product requirements. It is worth mentioning here that, the amount of silver released from AgNP-PA6 composites $\left(20 \mu \mathrm{g} / \mathrm{dm}^{2}\right)$ remained well below the permitted limits of $10 \mathrm{mg} / \mathrm{dm}^{2}$ as per European regulation for plastic packagings (EU No. 10/2011).[8]
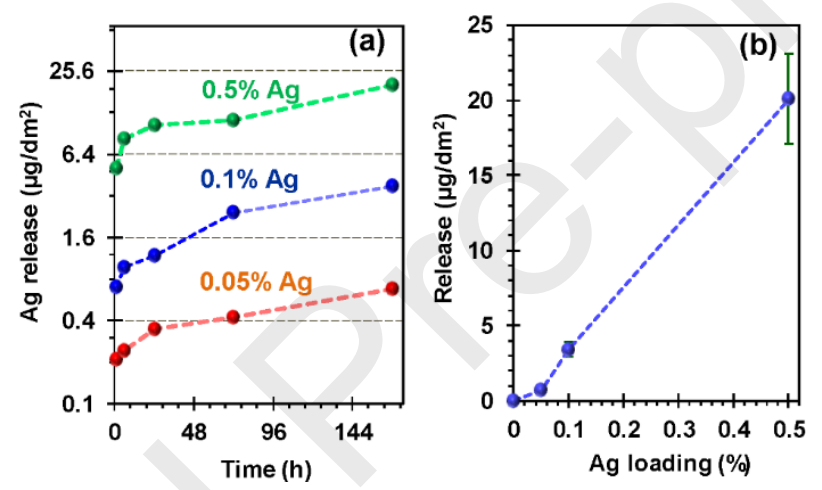

Fig. 10. (a) Silver release from spin-coated AgNP-PA6 composite films containing 0.05, 0.1 and $0.5 \%$ of AgNP. Release study was carried out $37^{\circ} \mathrm{C}$. (b) Relationship between silver release (at 168 hours) and AgNP concentration in spin-coated films.

We then performed the agar diffusion test to investigate the antimicrobial activity through silver release from the composite films. No obvious inhibition zone of L. monocytogenes was observed around the tested films even with AgNP up to $0.5 \%$ (Fig. 11a), suggesting very low release of silver incapable of being bactericidal. This is in good agreement with the very low silver release (upto $20 \mu \mathrm{g} / \mathrm{dm}^{2}$ ) observed during release study of AgNP-PA6 composite (Fig. 10). To investigate the antimicrobial activity through contact killing, bacterial suspension was loaded directly on the AgNP-PA6 composite film having 0.5 wt.\% Ag.[80] The viable cells showed more than $3.5 \log (99.96 \%)$ reduction compared to virgin PA6 film (control) within $2 \mathrm{~h}$ at $37^{\circ} \mathrm{C}$ (Fig. $\left.11 \mathrm{~b}-\mathrm{d}\right)$. These results demonstrate that AgNPs exert an antimicrobial effect mainly 
through a contact active mechanism with contributions from a release of silver ions at low level. Efficient antibacterial activity and very low silver leaching confirms the potential of AgNP-PA6 composite film as an antimicrobial packaging material even at a very low silver loading (0.5 wt.\%).
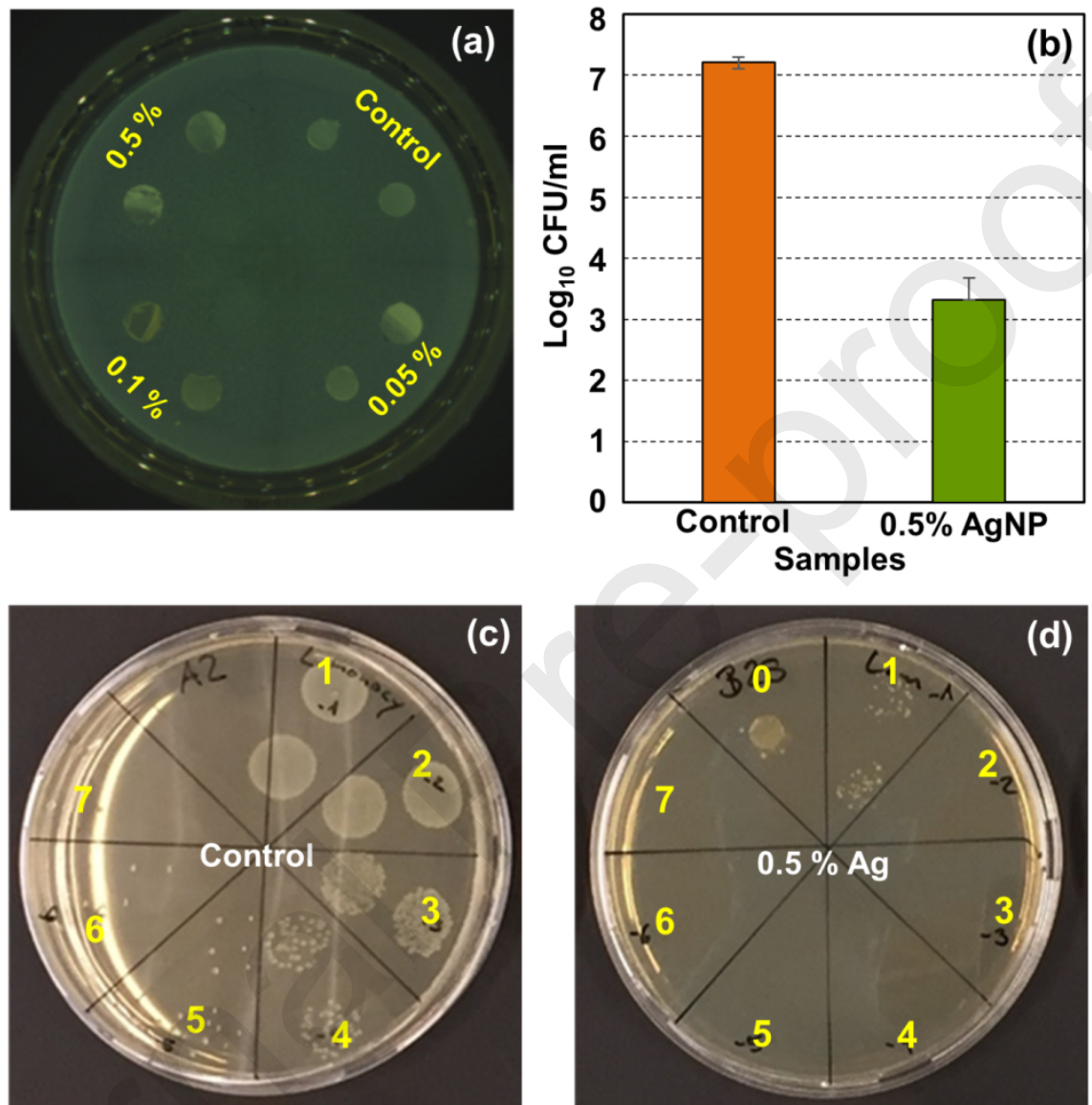

Fig. 11. (a) Agar diffusion test against food pathogen L. monocytogenes using AgNP-PA6 films with different silver content (after 1 day) showing no zone of inhibition. (b) Contact killing activity of PA6 without AgNP (control) and 0.5 wt.\% of AgNP. L. monocytogenes was incubated with PA6 samples for 2 hours in PBS under static condition at $37^{\circ} \mathrm{C}$, followed by careful removal of the suspensions. Subsequently all samples were washed with PBS twice to remove unattached bacteria. Adhered bacteria were released from surfaces by sonication and analyzed for viability by plating. Student's t-test $(\mathrm{p}<0.01)$ revealed a significant difference between PA6 without AgNP (control) and 0.5 wt.\% AgNP. Error bars represent the standard deviations of 6 measurements. (c) and (d) representative images of colonies produced from the viable cells released for the Control and AgNPPA6 composite film respectively. Yellow-labelled numbers indicate the dilution series. 


\section{Conclusions}

In this work, solventless method for in-situ silver nanoparticle synthesis within thermoplastic polymer matrices was demonstrated using a conventional polymer processing technique (melt mixing). Successful elimination of several energy and solvent consuming intermediate steps of nanocomposite preparation makes this a sustainable method. As a concept, AgNP-polymer composites were prepared by melt-mixing (kneading) of PA6, PP and PLA with $\mathrm{Ag}_{2} \mathrm{O}$ loadings up to $20 \%$. In case of PA6 and PLA, 10 min kneading at the melting temperature of the respective polymer was enough to achieve a complete reduction of $\mathrm{Ag}_{2} \mathrm{O}$ to $\mathrm{Ag}^{0}$ along with uniform distribution of AgNPs in the matrix. However, when PP was used as the matrix, only $60 \%$ reduction was achieved within 10 min processing, which may be due to incompatibility of PP matrix with $\mathrm{Ag}_{2} \mathrm{O}$. FTIR and GPC analysis confirmed the absence of any undesired degradation of polymer during in-situ AgNP synthesis. Even at a very low silver loading, (0.5\%), AgNP-PA6 composite displayed excellent antimicrobial activity against L. monocytogenes. The linear relationship between Ag loading and release offers the possibility for further control of Ag release based on application requirements. This solventless method of making polymer nanocomposites will be extended to other metals in the future. In addition tuning of silver release of such polymer nanocomposites by incorporation of other additives will also be investigated in future work.

Acknowledgements: Authors acknowledge the support of Mathias Lienhard in kneading experiments. This work was financially supported by Innosuisse, Switzerland (Project 18816.1 PFIW-IW) and EMS-CHEMIE AG, Switzerland. We also thank EMS-CHEMIE AG, Switzerland for GPC analysis of PA6 samples. 


\section{Appendix A. Supplementary material}

Supplementary data of this article can be found online at.

\section{Graphical abstract}

Solventless low-temperature thermal reduction

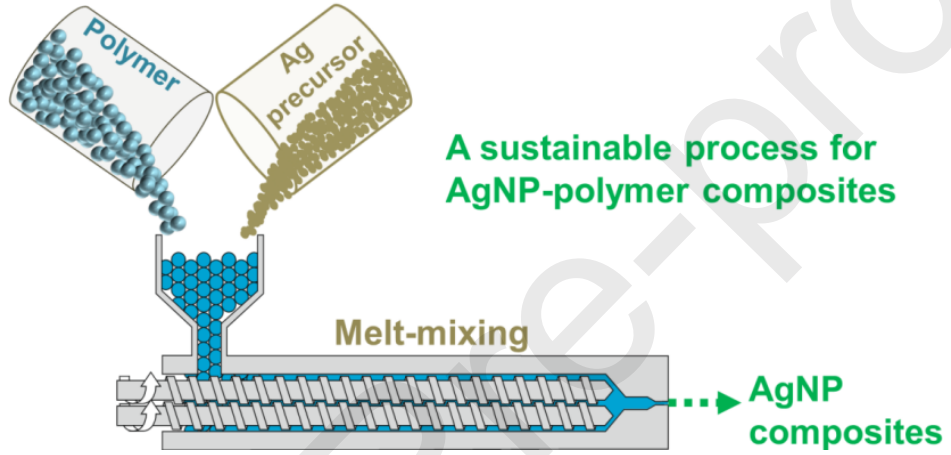




\section{References}

[1] L. Maretti, P.S. Billone, Y. Liu, J.C. Scaiano, Facile Photochemical Synthesis and Characterization of Highly Fluorescent Silver Nanoparticles, Journal of the American Chemical Society 131 (2009) 1397213980.

[2] Y. Li, Y. Wu, B.S. Ong, Facile Synthesis of Silver Nanoparticles Useful for Fabrication of High-Conductivity Elements for Printed Electronics, Journal of the American Chemical Society 127 (2005) 3266-3267.

[3] M.S. Islam, N. Akter, M.M. Rahman, C. Shi, M.T. Islam, H. Zeng, M.S. Azam, Mussel-Inspired Immobilization of Silver Nanoparticles toward Antimicrobial Cellulose Paper, ACS Sustainable Chemistry \& Engineering 6 (2018) 9178-9188.

[4] B. Le Ouay, F. Stellacci, Antibacterial activity of silver nanoparticles: A surface science insight, Nano Today 10 (2015) 339-354.

[5] N. Durán, M. Durán, M.B. de Jesus, A.B. Seabra, W.J. Fávaro, G. Nakazato, Silver nanoparticles: A new view on mechanistic aspects on antimicrobial activity, Nanomedicine: Nanotechnology, Biology and Medicine 12 (2016) 789-799.

[6] X.-F. Zhang, Z.-G. Liu, W. Shen, S. Gurunathan, Silver Nanoparticles: Synthesis, Characterization, Properties, Applications, and Therapeutic Approaches, International Journal of Molecular Sciences 17 (2016) 1534.

[7] Y. Kampmann, E. De Clerck, S. Kohn, D.K. Patchala, R. Langerock, J. Kreyenschmidt, Study on the antimicrobial effect of silver-containing inner liners in refrigerators, Journal of Applied Microbiology 104 (2008) 1808-1814.

[8] S.P. Deshmukh, S.M. Patil, S.B. Mullani, S.D. Delekar, Silver nanoparticles as an effective disinfectant: A review, Materials Science and Engineering: C 97 (2019) 954-965.

[9] M. Carbone, D.T. Donia, G. Sabbatella, R. Antiochia, Silver nanoparticles in polymeric matrices for fresh food packaging, Journal of King Saud University - Science 28 (2016) 273-279.

[10] S. Chernousova, M. Epple, Silver as Antibacterial Agent: Ion, Nanoparticle, and Metal, Angewandte Chemie International Edition 52 (2013) 1636-1653.

[11] A. Andrieux-Ledier, B. Tremblay, A. Courty, Synthesis of Silver Nanoparticles Using Different Silver Phosphine Precursors: Formation Mechanism and Size Control, The Journal of Physical Chemistry C 117 (2013) 14850-14857.

[12] M. Nishioka, M. Miyakawa, H. Kataoka, H. Koda, K. Sato, T.M. Suzuki, Continuous synthesis of monodispersed silver nanoparticles using a homogeneous heating microwave reactor system, Nanoscale 3 (2011) 2621-2626.

[13] R. Mohammadinejad, A. Shavandi, D.S. Raie, J. Sangeetha, M. Soleimani, S. Shokrian Hajibehzad, D. Thangadurai, R. Hospet, J.O. Popoola, A. Arzani, M.A. Gómez-Lim, S. Iravani, R.S. Varma, Plant molecular farming: production of metallic nanoparticles and therapeutic proteins using green factories, Green Chemistry 21 (2019) 1845-1865.

[14] S. Iravani, Green synthesis of metal nanoparticles using plants, Green Chemistry 13 (2011) 2638-2650. [15] M.N. Nadagouda, N. Iyanna, J. Lalley, C. Han, D.D. Dionysiou, R.S. Varma, Synthesis of Silver and Gold Nanoparticles Using Antioxidants from Blackberry, Blueberry, Pomegranate, and Turmeric Extracts, ACS Sustainable Chemistry \& Engineering 2 (2014) 1717-1723. 
[16] M. Goudarzi, N. Mir, M. Mousavi-Kamazani, S. Bagheri, M. Salavati-Niasari, Biosynthesis and characterization of silver nanoparticles prepared from two novel natural precursors by facile thermal decomposition methods, Scientific Reports 6 (2016) 32539.

[17] S.Y. Yeo, S.H. Jeong, Preparation and characterization of polypropylene/silver nanocomposite fibers, Polymer International 52 (2003) 1053-1057.

[18] S. Sánchez-Valdes, H. Ortega-Ortiz, L.F. Ramos-de Valle, F.J. Medellín-Rodríguez, R. Guedea-Miranda, Mechanical and antimicrobial properties of multilayer films with a polyethylene/silver nanocomposite layer, Journal of Applied Polymer Science 111 (2009) 953-962.

[19] H. Chi, J. Xue, C. Zhang, H. Chen, L. Li, Y. Qin, High Pressure Treatment for Improving Water Vapour Barrier Properties of Poly(lactic acid)/Ag Nanocomposite Films, Polymers 10 (2018) 1011.

[20] Z. Chu, T. Zhao, L. Li, J. Fan, Y. Qin, Characterization of Antimicrobial Poly (Lactic Acid)/NanoComposite Films with Silver and Zinc Oxide Nanoparticles, Materials 10 (2017) 659.

[21] C. Aymonier, U. Schlotterbeck, L. Antonietti, P. Zacharias, R. Thomann, J.C. Tiller, S. Mecking, Hybrids of silver nanoparticles with amphiphilic hyperbranched macromolecules exhibiting antimicrobial properties, Chemical Communications (2002) 3018-3019.

[22] A. Emamifar, M. Kadivar, M. Shahedi, S. Soleimanian-Zad, Evaluation of nanocomposite packaging containing $\mathrm{Ag}$ and $\mathrm{ZnO}$ on shelf life of fresh orange juice, Innovative Food Science \& Emerging Technologies 11 (2010) 742-748.

[23] C. Damm, H. Münstedt, A. Rösch, The antimicrobial efficacy of polyamide 6/silver-nano- and microcomposites, Materials Chemistry and Physics 108 (2008) 61-66.

[24] X. Xin, P. Li, Y. Zhu, L. Shi, J. Yuan, J. Shen, Mussel-Inspired Surface Functionalization of PET with Zwitterions and Silver Nanoparticles for the Dual-Enhanced Antifouling and Antibacterial Properties, Langmuir 35 (2019) 1788-1797.

[25] D. Somayajula, A. Agarwal, A.K. Sharma, A.E. Pall, S. Datta, G. Ghosh, In Situ Synthesis of Silver Nanoparticles within Hydrogel-Conjugated Membrane for Enhanced Antibacterial Properties, ACS Applied Bio Materials 2 (2019) 665-674.

[26] A. Kumar, P.K. Vemula, P.M. Ajayan, G. John, Silver-nanoparticle-embedded antimicrobial paints based on vegetable oil, Nature Materials 7 (2008) 236.

[27] S. Porel, S. Singh, S.S. Harsha, D.N. Rao, T.P. Radhakrishnan, Nanoparticle-Embedded Polymer: In Situ Synthesis, Free-Standing Films with Highly Monodisperse Silver Nanoparticles and Optical Limiting, Chemistry of Materials 17 (2005) 9-12.

[28] P. Raveendran, J. Fu, S.L. Wallen, Completely "Green" Synthesis and Stabilization of Metal Nanoparticles, Journal of the American Chemical Society 125 (2003) 13940-13941.

[29] B. Carlberg, L.-L. Ye, J. Liu, Polymer-metal nanofibrous composite for thermal management of microsystems, Materials Letters 75 (2012) 229-232.

[30] L. Longenberger, G. Mills, Formation of Metal Particles in Aqueous Solutions by Reactions of Metal Complexes with Polymers, The Journal of Physical Chemistry 99 (1995) 475-478.

[31] Z. Wang, C. Xu, M. Zhao, C. Zhao, One-pot synthesis of narrowly distributed silver nanoparticles using phenolic-hydroxyl modified chitosan and their antimicrobial activity, RSC Advances 4 (2014) 47021-47030.

[32] X. Huang, Y. Pang, Y. Liu, Y. Zhou, Z. Wang, Q. Hu, Green synthesis of silver nanoparticles with high antimicrobial activity and low cytotoxicity using catechol-conjugated chitosan, RSC Advances 6 (2016) 64357-64363.

[33] X. Huang, X. Bao, Y. Liu, Z. Wang, Q. Hu, Catechol-Functional Chitosan/Silver Nanoparticle Composite as a Highly Effective Antibacterial Agent with Species-Specific Mechanisms, Scientific Reports 7 (2017) 1860.

[34] K.-L. Liang, Y.-C. Wang, W.-L. Lin, J.-J. Lin, Polymer-assisted self-assembly of silver nanoparticles into interconnected morphology and enhanced surface electric conductivity, RSC Advances 4 (2014) 1509815103. 
[35] A.V. Gaikwad, T.K. Rout, In situ synthesis of silver nanoparticles in polyetherimide matrix and its application in coatings, Journal of Materials Chemistry 21 (2011) 1234-1239.

[36] D.Y. Zhang, J. Liu, Y.S. Shi, Y. Wang, H.F. Liu, Q.L. Hu, L. Su, J. Zhu, Antifouling polyimide membrane with surface-bound silver particles, Journal of Membrane Science 516 (2016) 83-93.

[37] Q. Zhang, D. Wu, S. Qi, Z. Wu, X. Yang, R. Jin, Preparation of ultra-fine polyimide fibers containing silver nanoparticles via in situ technique, Materials Letters 61 (2007) 4027-4030.

[38] Z. Zhang, L. Zhang, S. Wang, W. Chen, Y. Lei, A convenient route to polyacrylonitrile/silver nanoparticle composite by simultaneous polymerization-reduction approach, Polymer 42 (2001) 83158318.

[39] M. Sangermano, Y. Yagci, G. Rizza, In Situ Synthesis of Silver-Epoxy Nanocomposites by Photoinduced Electron Transfer and Cationic Polymerization Processes, Macromolecules 40 (2007) 8827-8829.

[40] Y. Yagci, M. Sangermano, G. Rizza, A visible light photochemical route to silver-epoxy nanocomposites by simultaneous polymerization-reduction approach, Polymer 49 (2008) 5195-5198.

[41] M. Nakano, T. Fujiwara, N. Koga, Thermal Decomposition of Silver Acetate: Physico-Geometrical Kinetic Features and Formation of Silver Nanoparticles, The Journal of Physical Chemistry C 120 (2016) 8841-8854.

[42] C. Damm, H. Münstedt, A. Rösch, Long-term antimicrobial polyamide 6/silver-nanocomposites, Journal of Materials Science 42 (2007) 6067-6073.

[43] C. Triebel, S. Vasylyev, C. Damm, H. Stara, C. Özpınar, S. Hausmann, W. Peukert, H. Münstedt, Polyurethane/silver-nanocomposites with enhanced silver ion release using multifunctional invertible polyesters, Journal of Materials Chemistry 21 (2011) 4377-4383.

[44] G.C. Hood, G.W. Murphy, The decomposition of silver oxide-An autocatalytic reaction, Journal of Chemical Education 26 (1949) 169.

[45] P.J. Herley, E.G. Prout, The Thermal Decomposition of Silver Oxide, Journal of the American Chemical Society 82 (1960) 1540-1543.

[46] B.V. L'Vov, Kinetics and mechanism of thermal decomposition of silver oxide, Thermochimica Acta 333 (1999) 13-19.

[47] D. Jelić, J. Penavin-Škundrić, D. Majstorović, S. Mentus, The thermogravimetric study of silver(I) oxide reduction by hydrogen, Thermochimica Acta 526 (2011) 252-256.

[48] G. Schimo, A.M. Kreuzer, A.W. Hassel, Morphology and size effects on the reduction of silver oxide by hydrogen, physica status solidi (a) 212 (2015) 1202-1209.

[49] T.D. Fornes, P.J. Yoon, D.R. Paul, Polymer matrix degradation and color formation in melt processed nylon 6/clay nanocomposites, Polymer 44 (2003) 7545-7556.

[50] M. Guillemot, B. Oury, S. Melin, Identifying thermal breakdown products of thermoplastics, Journal of Occupational and Environmental Hygiene 14 (2017) 551-561.

[51] T. Karstens, V. Rossbach, Thermo-oxidative degradation of polyamide 6 and 6,6. Kinetics of the formation and inhibition of UV/VIS-active chromophores, Die Makromolekulare Chemie 190 (1989) 30333053.

[52] P. Marechal, R. Legras, J.M. Dekoninck, Postcondensation and oxidation processes in molten polyamide 6, Journal of Polymer Science Part A: Polymer Chemistry 31 (1993) 2057-2067.

[53] J.F. Robert L. Snyder, Hans J. Bunge, Defect and Microstructure Analysis by Diffraction, Oxford University Press, New York, 1999.

[54] A. Coelho, TOPAS and TOPAS-Academic: an optimization program integrating computer algebra and crystallographic objects written in C++, Journal of Applied Crystallography 51 (2018) 210-218.

[55] G.I.N. Waterhouse, G.A. Bowmaker, J.B. Metson, The thermal decomposition of silver (I, III) oxide: A combined XRD, FT-IR and Raman spectroscopic study, Physical Chemistry Chemical Physics 3 (2001) 38383845. 
[56] R. Szczęsny, E. Szłyk, Thermal decomposition of some silver(I) carboxylates under nitrogen atmosphere, Journal of Thermal Analysis and Calorimetry 111 (2013) 1325-1330.

[57] M.D. Judd, B.A. Plunkett, M.I. Pope, The thermal decomposition of calcium, sodium, silver and copper(II) acetates, Journal of thermal analysis 6 (1974) 555-563.

[58] K.H. Stern, High Temperature Properties and Decomposition of Inorganic Salts Part 3, Nitrates and Nitrites, Journal of Physical and Chemical Reference Data 1 (1972) 747-772.

[59] S. Sirohi, A. Mittal, R. Nain, N. Jain, R. Singh, S. Dobhal, B. Pani, D. Parida, Effect of nanoparticle shape on the conductivity of Ag nanoparticle poly(vinyl alcohol) composite films, Polymer International 68 (2019) 1961-1967.

[60] P. Praus, M. Turicová, M. Klementová, Preparation of silver-montmorillonite nanocomposites by reduction with formaldehyde and borohydride, Journal of the Brazilian Chemical Society 20 (2009) 13511357.

[61] K.-S. Chou, C.-Y. Ren, Synthesis of nanosized silver particles by chemical reduction method, Materials Chemistry and Physics 64 (2000) 241-246.

[62] C. Cascio, O. Geiss, F. Franchini, I. Ojea-Jimenez, F. Rossi, D. Gilliland, L. Calzolai, Detection, quantification and derivation of number size distribution of silver nanoparticles in antimicrobial consumer products, Journal of Analytical Atomic Spectrometry 30 (2015) 1255-1265.

[63] T.G.F. Souza, V.S.T. Ciminelli, N.D.S. Mohallem, A comparison of TEM and DLS methods to characterize size distribution of ceramic nanoparticles, Journal of Physics: Conference Series 733 (2016) 012039.

[64] M.V. Lock, B.F. Sagar, Autoxidation of N-alkylamides. Part I. N-Acylamides as oxidation products, Journal of the Chemical Society B: Physical Organic (1966) 690-696.

[65] W.H. Sharkey, W.E. Mochel, Mechanism of the Photoöxidation of Amides, Journal of the American Chemical Society 81 (1959) 3000-3005.

[66] M. Oliveira, E. Santos, A. Araújo, G.J.M. Fechine, A.V. Machado, G. Botelho, The role of shear and stabilizer on PLA degradation, Polymer Testing 51 (2016) 109-116.

[67] Y. Zhao, C. Tao, G. Xiao, H. Su, Controlled synthesis and wastewater treatment of Ag2O/TiO2 modified chitosan-based photocatalytic film, RSC Advances 7 (2017) 11211-11221.

[68] T. Arakawa, F. Nagatoshi, N. Arai, Melting behavior and morphology of drawn nylon 6, Journal of Polymer Science Part A-2: Polymer Physics 7 (1969) 1461-1472.

[69] A.-C. Baudouin, J. Devaux, C. Bailly, Localization of carbon nanotubes at the interface in blends of polyamide and ethylene-acrylate copolymer, Polymer 51 (2010) 1341-1354.

[70] V. Khoshkava, M.R. Kamal, Effect of Surface Energy on Dispersion and Mechanical Properties of Polymer/Nanocrystalline Cellulose Nanocomposites, Biomacromolecules 14 (2013) 3155-3163.

[71] A. Cayla, C. Campagne, M. Rochery, E. Devaux, Electrical, rheological properties and morphologies of biphasic blends filled with carbon nanotubes in one of the two phases, Synthetic Metals 161 (2011) 10341042.

[72] D.Y. Kwok, L.K. Cheung, C.B. Park, A.W. Neumann, Study on the surface tensions of polymer melts using axisymmetric drop shape analysis, Polymer Engineering \& Science 38 (1998) 757-764.

[73] D. Vaillant, J. Lacoste, G. Dauphin, The oxidation mechanism of polypropylene: contribution of 13CNMR spectroscopy, Polymer Degradation and Stability 45 (1994) 355-360.

[74] A. Hoff, S. Jacobsson, Thermal oxidation of polypropylene in the temperature range of $120-280^{\circ} \mathrm{C}$, Journal of Applied Polymer Science 29 (1984) 465-480.

[75] F. Dogan, Thermal Oxidation of Polypropylene and Modified Polypropylene - Structure Effects 2012.

[76] Y. Sun, Y. Xia, Large-Scale Synthesis of Uniform Silver Nanowires Through a Soft, Self-Seeding, Polyol Process, Advanced Materials 14 (2002) 833-837.

[77] Y. Xiong, A.R. Siekkinen, J. Wang, Y. Yin, M.J. Kim, Y. Xia, Synthesis of silver nanoplates at high yields by slowing down the polyol reduction of silver nitrate with polyacrylamide, Journal of Materials Chemistry 17 (2007) 2600-2602. 
[78] A. Alonso, X. Muñoz-Berbel, N. Vigués, R. Rodríguez-Rodríguez, J. Macanás, M. Muñoz, J. Mas, D.N. Muraviev, Superparamagnetic Ag@Co-Nanocomposites on Granulated Cation Exchange Polymeric Matrices with Enhanced Antibacterial Activity for the Environmentally Safe Purification of Water, Advanced Functional Materials 23 (2013) 2450-2458.

[79] Y.-S. Ko, Y.H. Joe, M. Seo, K. Lim, J. Hwang, K. Woo, Prompt and synergistic antibacterial activity of silver nanoparticle-decorated silica hybrid particles on air filtration, Journal of Materials Chemistry B 2 (2014) 6714-6722.

[80] A.V. Fuchs, S. Ritz, S. Pütz, V. Mailänder, K. Landfester, U. Ziener, Bioinspired phosphorylcholine containing polymer films with silver nanoparticles combining antifouling and antibacterial properties, Biomaterials Science 1 (2013) 470-477.

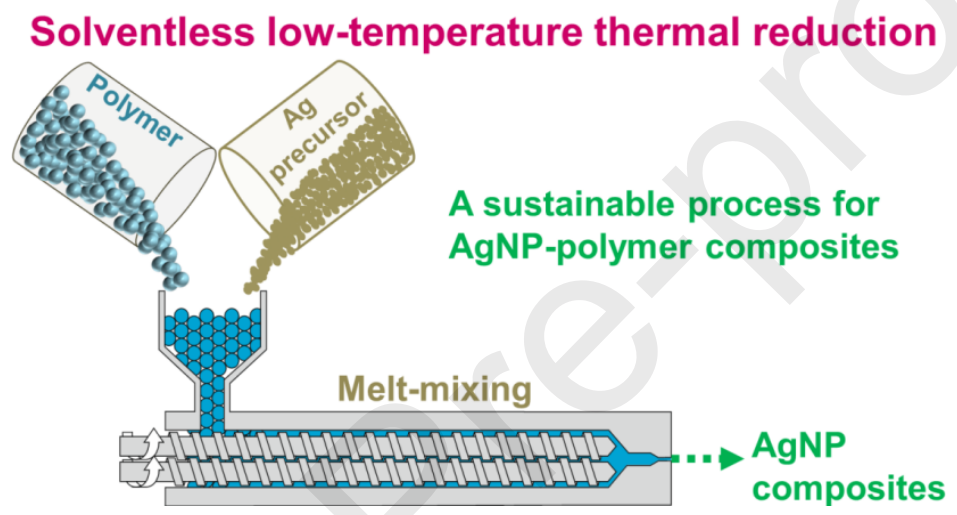

\section{Highlights}

- Reduction temperature of silver precursors can be decreased significantly with the assistance of polymer.

- Nanosilver-polymer composites can be achieved during thermal processing of polymers using conventional equipment.

- Polymer assisted thermal reduction process can achieve reduction of silver precursors in a quick time.

- Surface energy of polymer melt has a significant influence on the reduction of silver precursors.

- Antimicrobial efficacy of the Nanosilver-polymer composites against common food pathogen was proven. 
